\title{
New Volatile Perfluorinated Amidine-Carboxylate Copper(II) Complexes as Promising Precursors in CVD and FEBID Methods
}

\author{
Katarzyna Madajska (D) and Iwona Barbara Szymańska *(D) \\ Department of Chemistry, Nicolaus Copernicus University in Torun, Gagarina 7, 87-100 Torun, Poland; \\ 502533@doktorant.umk.pl \\ * Correspondence: pola@umk.pl; Tel.: +48-56-611-4317
}

check for updates

Citation: Madajska, K.; Szymańska, I.B. New Volatile Perfluorinated Amidine-Carboxylate Copper(II) Complexes as Promising Precursors in CVD and FEBID Methods. Materials 2021, 14, 3145. https:// doi.org/10.3390/ma14123145

Academic Editor: Piotr Smoleński

Received: 26 April 2021

Accepted: 2 June 2021

Published: 8 June 2021

Publisher's Note: MDPI stays neutral with regard to jurisdictional claims in published maps and institutional affiliations.

Copyright: (c) 2021 by the authors. Licensee MDPI, Basel, Switzerland. This article is an open access article distributed under the terms and conditions of the Creative Commons Attribution (CC BY) license (https:// creativecommons.org/licenses/by/ $4.0 /)$.
Abstract: In the present study, we have synthesised and characterised newly copper(II) complexes with the general formula $\left[\mathrm{Cu}_{2}\left(\mathrm{NH}_{2}(\mathrm{NH}=) \mathrm{CC}_{2} \mathrm{~F}_{5}\right)_{2}\left(\mu-\mathrm{O}_{2} \mathrm{CR}_{\mathrm{F}}\right)_{4}\right]$, where $\mathrm{R}_{\mathrm{F}}=\mathrm{CF}_{3}, \mathrm{C}_{2} \mathrm{~F}_{5}, \mathrm{C}_{3} \mathrm{~F}_{7}, \mathrm{C}_{4} \mathrm{~F}_{9}$. Infrared spectroscopy, mass spectrometry with electron ionisation (EI MS), and density-functional theory (DFT) calculations were used to confirm compounds' composition and structure. The volatility of the compounds was studied using thermal analysis (TGA), EI MS mass spectrometry, variable temperature infrared spectroscopy (VT IR), and sublimation experiments. Research has revealed that these compounds are the source of metal carriers in the gas phase. The thermal decomposition mechanism over reduced pressure was proposed. TGA studies demonstrated that copper transfer to the gaseous phase occurs even at atmospheric pressure. Two selected complexes $\left[\mathrm{Cu}_{2}\left(\mathrm{NH}_{2}(\mathrm{NH}=) \mathrm{CC}_{2} \mathrm{~F}_{5}\right)_{2}(\mu-\right.$ $\left.\left.\mathrm{O}_{2} \mathrm{CC}_{2} \mathrm{~F}_{5}\right)_{4}\right]$ and $\left[\mathrm{Cu}_{2}\left(\mathrm{NH}_{2}(\mathrm{NH}=) \mathrm{CC}_{2} \mathrm{~F}_{5}\right)_{2}\left(\mu-\mathrm{O}_{2} \mathrm{CC}_{3} \mathrm{~F}_{7}\right)_{4}\right]$ were successful used as chemical vapour deposition precursors. Copper films were deposited with an evaporation temperature of $393 \mathrm{~K}$ and $453 \mathrm{~K}$, respectively, and a decomposition temperature in the range of 573-633 K without the use of hydrogen. The microscopic observations made to investigate the interaction of the $\left[\mathrm{Cu}_{2}\left(\mathrm{NH}_{2}(\mathrm{NH}=) \mathrm{CC}_{2} \mathrm{~F}_{5}\right)_{2}\left(\mu-\mathrm{O}_{2} \mathrm{CC}_{2} \mathrm{~F}_{5}\right)_{4}\right]$ with the electron beam showed that the ligands are completely lost under transmission electron microscopy analysis conditions $(200 \mathrm{keV})$, and the final product is copper(II) fluoride. In contrast, the beam energy in scanning electron microscopy (20 keV) was insufficient to break all coordination bonds. It was shown that the $\mathrm{Cu}-\mathrm{O}$ bond is more sensitive to the electron beam than the $\mathrm{Cu}-\mathrm{N}$ bond.

Keywords: chemical vapour deposition; focused electron beam induced deposition; volatile compounds; volatility study; nanomaterials; electron interactions; copper fluoride; thermal properties

\section{Introduction}

Nowadays, copper compounds are used, for example, to design hybrid organicinorganic materials [1-3], anticancer agents [4,5], and sensors [6,7]. Additionally, copper complexes are used as model compounds and tested as antimicrobial agents [8-10].

On the other hand, copper nanostructures are used, for example, in electronics [11-13], plasmonics [14,15], catalysis [16-18], and as antibacterial agents [19,20]. These structures can be obtained by gas-assisted methods such as chemical vapour deposition (CVD) [21-23] and focused electron beam induced deposition (FEBID) [24-26]. CVD is a process where one or more volatile precursors are transported in the vapour carrier gas to the reactor chamber, where they decompose on a heated substrate and deposit a solid material [27]. In FEBID, the precursor is supplied without the use of carrier gas, then the adsorbed compound is dissociated in the focus of an electron beam provided by a scanning or transmission electron microscope (SEM/TEM) [28]. For the FEBID deposition of metals, CVD precursors are often tested. However, in addition to being sufficiently volatile, the compound must also decompose under the influence of an electron beam [29]. In copper FEBID, several complexes previously used as CVD precursors, such as [Cu(hfac)(VTMS)], 
[Cu(hfac)(MHY)], and $[\mathrm{Cu}(\mathrm{hfac})(\mathrm{DMB})]$ of $\mathrm{Cu}(\mathrm{I}) ;\left[\mathrm{Cu}(\text { tbaoac })_{2}\right],\left[\mathrm{Cu}(\mathrm{hfac})_{2}\right] \cdot \mathrm{H}_{2} \mathrm{O}$, and most recently $\left[\mathrm{Cu}_{2}\left(\mu-\mathrm{O}_{2} \mathrm{CC}_{2} \mathrm{~F}_{5}\right)_{4}\right]$ of $\mathrm{Cu}(\mathrm{II})$, were applied, but the purity $(10-26$ at.\%) of the formed deposits remains a problem [30-33].

There are no literature data about the synthesis of $\mathrm{Cu}(\mathrm{II})$ perfluorinated amidinate and heteroleptic amidine-carboxylate compounds and research on their volatility to the best of our knowledge. In the available literature, only silver(I) and mercury(II) compounds with perfluorinated amidinates are known: $\left.\left[\mathrm{Ag}_{2}(\mathrm{NH})_{2} \mathrm{CCF}_{3}\right)_{2}\right],\left[\mathrm{Ag}_{2}\left((\mathrm{NH})_{2} \mathrm{CC}_{2} \mathrm{~F}_{5}\right)_{2}\right]$, and $\left[\mathrm{Hg}\left((\mathrm{NH})_{2} \mathrm{CC}_{2} \mathrm{~F}_{5}\right)_{2}\right]$, which however, have not been tested for use in vapor deposition methods [34]. Only copper(I) amidinate complexes with non-fluorinated ligands of the general formula $\left[\mathrm{Cu}_{2}(\mathrm{AMD})_{2}\right]$, known from the ALD (atomic layer deposition) process [35], have been tested in the CVD process. For example, when $\left[\mathrm{Cu}_{2}(\mathrm{i}-\mathrm{Pr}-\mathrm{MeAMD})_{2}\right]$ was vaporised at $368 \mathrm{~K}$ and hydrogen was used as a reducing gas, pure copper films were obtained in the temperature range 473-573 K [36]. Using the same precursor, copper films were deposited on steel, silicon, and $\mathrm{SiO}_{2} / \mathrm{Si}$ substrates at $473-623 \mathrm{~K}$, at a total pressure of $1333 \mathrm{~Pa}$ with hydrogen as a reactive gas [37]. On the other hand, in 2019, $\left(N, N^{\prime}\right.$-di-secbutylacetamidinato)copper(I) was used to produce $\mathrm{Cu}_{2} \mathrm{O}$ thin films in a water assistance process in a low-temperature range of 398-473 K [38]. In all of the above-mentioned CVD processes, although copper(I) compounds were used, which are often spontaneously disproportionate to copper(0), it was necessary to use hydrogen as a reducing agent. Furthermore, both the synthesis and the manipulation of the used compounds should be carried out under inert gas [39].

It is known that fluorinated ligands favour thermal stability and vapour pressure [40]. Copper CVD precursors containing perfluorinated carboxylates and $\mathrm{N}$-donor ligands are known. $\left[\mathrm{Cu}_{2}\left({ }^{\mathrm{t}} \mathrm{BuNH}_{2}\right)_{2}\left(\mu-\mathrm{O}_{2} \mathrm{CR}_{\mathrm{F}}\right)_{4}\right]\left(\mathrm{R}_{\mathrm{F}}=\mathrm{C}_{\mathrm{n}} \mathrm{F}_{2 n+1}, n=1-6\right)$ were the source of volatile copper species: $\left.\left[\mathrm{Cu}_{2}\left({ }^{\mathrm{t}} \mathrm{BuNH}\right)_{2}\right)_{2}\left(\mu-\mathrm{O}_{2} \mathrm{CR}_{\mathrm{F}}\right)_{4}\right]$ and $\left[\mathrm{Cu}_{2}\left(\mathrm{O}_{2} \mathrm{CR}_{\mathrm{F}}\right)_{2}\right]$, which were transported in the gas phase in the temperature range of $473-533 \mathrm{~K}$. Metallic copper films were obtained between $623 \mathrm{~K}$ and $733 \mathrm{~K}$ without an additional reducing agent [41,42].

On the other hand, in their 2008 paper, Brown et al. reported the amidinate-carboxylate complexes of dimolybdenium(II) and ditungsten(II) $\left[\mathrm{M}_{2}\left(\mathrm{O}_{2} \mathrm{CMe}\right)_{2}\left(\left(\mathrm{~N}^{\mathrm{i} P r}\right)_{2} \mathrm{CR}\right)_{2}\right]$ obtained from the reaction of the $\left[\mathrm{M}_{2}\left(\mathrm{O}_{2} \mathrm{CMe}\right)_{4}\right]$ and the lithium amidinates $\mathrm{Li}\left\{\left(\mathrm{N}^{\mathrm{i}} \mathrm{Pr}\right)_{2} \mathrm{CR}\right\}$, where $\mathrm{M}=\mathrm{Mo}, \mathrm{W}$ and $\mathrm{R}=\mathrm{Me}$ or $\mathrm{M}=\mathrm{Mo}$ and $\mathrm{R}=-\mathrm{C} \equiv \mathrm{C}^{\mathrm{t}} \mathrm{Bu},-\mathrm{C} \equiv \mathrm{CPh}$, and $-\mathrm{C} \equiv \mathrm{C}-\mathrm{Fc}(\mathrm{Fc}=$ 1-ferrocenyl) [43]. In other studies [Mo(amidinate $\left.)\left(\mathrm{O}_{2} \mathrm{CR}\right)_{3}\right]$ or $\left.\left[\mathrm{W}_{2} \text { (amidinate }\right)_{2}\left(\mathrm{O}_{2} \mathrm{CR}\right)_{2}\right]$ complexes with bridging amidinate were obtained in reaction of $\left[\mathrm{M}_{2}\left(\mathrm{O}_{2} \mathrm{CR}\right)_{4}\right](\mathrm{M}=\mathrm{Mo}, \mathrm{W}$, $\left.\mathrm{R}=\mathrm{CF}_{3}\right)$ with one and two equivalents of $\operatorname{Li}\left\{\left(\mathrm{N}-2,6-{ }^{\mathrm{i}} \mathrm{Pr}_{2} \mathrm{C}_{6} \mathrm{H}_{3}\right)_{2} \mathrm{CH}\right\}(\mathrm{THF})_{2}$, respectively [44] However, in the mechanochemical reaction of unsymmetrical $N, N^{\prime}$-diarylformamidine ligands (Ar-amidine), for example, $N$-(2-methoxyphenyl)- $N^{\prime}$-2,6-dichorophenyl)-formamidine with copper(II) acetate and zinc(II) acetate, paddle wheel complexes of general formula $\left[\mathrm{Zn}_{2}(\text { Ar-amidine })_{2}(\mathrm{OAc})_{4}\right]$ and $\left[\mathrm{Cu}_{2}(\mathrm{Ar} \text {-amidine })_{2}(\mathrm{OAc})_{4}\right]$ were synthesised. In the obtained complexes, the $\mathrm{N}$-coordinated ligand in the axial position remained protonated [45].

We decided to synthesise compounds containing a perfluorinated carboxylate and a perfluorinated amidine as a secondary ligand in the axial position based on the previously mentioned literature results. We wanted to investigate how the volatility and thermal stability of the compound would be affected by introducing the perfluorinated amidine instead of the previously used amine with bulky group. In this paper, we discuss the synthesis of novel copper(II) complexes with the general formula $\left[\mathrm{Cu}_{2}\left(\mathrm{NH}_{2}(\mathrm{NH}=) \mathrm{CC}_{2} \mathrm{~F}_{5}\right)_{2}\left(\mathrm{O}_{2} \mathrm{CR}_{\mathrm{F}}\right)_{4}\right]$, where $\mathrm{R}_{\mathrm{F}}=\mathrm{CF}_{3}, \mathrm{C}_{2} \mathrm{~F}_{5}, \mathrm{C}_{3} \mathrm{~F}_{7}, \mathrm{C}_{4} \mathrm{~F}_{9}$. For simplicity, the abbreviation $\mathrm{AMDH}$ for $\mathrm{C}_{2} \mathrm{~F}_{5} \mathrm{C}(=\mathrm{NH}) \mathrm{NH}_{2}$ is used in this work. We also describe the structural characteristics and thermal properties of the new compounds. Importantly, we examined the volatility of the compounds and their interactions with an electron beam. We selected the most promising compounds and used them in preliminary chemical vapour deposition experiments based on volatility studies.

\section{Materials and Methods}

$\mathrm{CuCO}_{3} \cdot \mathrm{Cu}(\mathrm{OH})_{2}(>95 \%)$, anhydrous acetonitrile $(99.8 \%), \mathrm{CF}_{3} \mathrm{COOH}(99 \%)$, and $\mathrm{RCOOH}\left(\mathrm{R}=\mathrm{C}_{\mathrm{n}} \mathrm{F}_{2 \mathrm{n}+1} ; n=2-4 ; 97-98 \%\right)$ were purchased from Sigma Aldrich (Saint Louis, 
$\mathrm{MO}, \mathrm{USA})$ and used as received. Pentafluoropropylamidine $\mathrm{C}_{2} \mathrm{~F}_{5} \mathrm{C}(=\mathrm{NH}) \mathrm{NH}_{2}(\mathrm{AMDH})$ $(98.7 \%)$ was purchased from Apollo Scientific (Stockport, UK) and used as received. Copper(II) carboxylates $\left[\mathrm{Cu}_{2}\left(\mu-\mathrm{O}_{2} \mathrm{CR}_{\mathrm{F}}\right)_{4}\right]$, where $\mathrm{R}_{\mathrm{F}}=\mathrm{C}_{\mathrm{n}} \mathrm{F}_{2 \mathrm{n}+1}, n=1-4$, were prepared as earlier reported [46].

\subsection{Instrumentation}

Mass spectra using a Finnigan MAT 95 mass spectrometer, Waltham, MA, USA and electron ionisation (EI) method were registered over the temperature range of 303-623 $\mathrm{K}$. The $\mathrm{Cu}$ content was determined with an iCE3300 FL atomic absorption spectrometer Thermo Fisher Scientific, Waltham, MA, USA. The content of $C$ was found out with a Vario MACRO CHN ELEMENTAR Analysensysteme GmbH, Langenselbold, Germany. IR spectra were measured on a Vertex 70V spectrometer (Bruker Optik, Leipzig, Germany) using a reflective-single reflection diamond ATR unit $\left(400-4000 \mathrm{~cm}^{-1}\right)$. Thermal studies (TGA/DTA) were performed on an SDT 2960 TA analyser (New Castle, DE, USA) (dry $\mathrm{N}_{2}$; heating rate $2.5 \mathrm{~K} / \mathrm{min}$, heating range up to $598-692 \mathrm{~K}$; sample mass $7-13 \mathrm{mg}$ ). Variable temperature infrared spectra (VT IR) were registered using a PerkinElmer Spectrum 2000 spectrometer (Waltham, MA, USA) over the range $400-4000 \mathrm{~cm}^{-1}$ with a medium slit width and a peak resolution of $2.0 \mathrm{~cm}^{-1}$. The glass vessel with the precursor sample $(\sim 100 \mathrm{mg}$ ) was placed in the homemade reactor tube and heated (from 303 to $753 \mathrm{~K}$ ) under a dynamic vacuum ( $p=10^{-1}$ mbar). IR spectra of vapours collected at selected temperatures were registered. Preliminary deposition experiments were carried out using the homemade horizontal hot-wall CVD reactor. Copper films were grown on $\mathrm{Si}(111)$ in argon within $60 \mathrm{~min}$. The vaporisation temperatures $\mathrm{T}_{\mathrm{V}}$ were $393 \mathrm{~K}$ and $453 \mathrm{~K}$, whereas the deposition temperature values $T_{D}$ were $593 \mathrm{~K}$ and $633 \mathrm{~K}$. The morphology and composition studies of obtained materials were performed using scanning electron microscopy: SEMLEO 1430VP, Ltd., Cambridge, UK (operating voltage $20 \mathrm{kV}$ ) equipped with an energy dispersive X-ray spectrometer (EDS) Quantax 200 with detector XFlash 4010 (Bruker AXS microanalysis $\mathrm{GmbH}$, Berlin, Germany). XRD data were collected with a Philips X'PERT diffractometer with an $X^{\prime}$ Celerator Scientific detector (Malvern Panalytical Ltd., Malvern, UK). Diffractogramms were measured in the $10-100^{\circ} 2 \theta$ range, using $\mathrm{Cu} \mathrm{K}_{\alpha}$ irradiation and sample spinning (step size $-0.0167^{\circ}$, program. res. slit- 0.5 , measuring time $-30 \mathrm{~s}$ per point). SEM images were registered using Quanta 3D FEG (FEI, Hillsboro, OR, USA). Transmission electron microscopy (TEM G2 F20X-Twin 200 kVFEI, Hillsboro, OR, USA) was used to determine the composition of the thermal analysis residue, confirm the composition of the deposited materials, and test the sensitivity of compounds to the high-energy electron beam. A sample for TEM testing was prepared by dissolving in anhydrous ethanol (99.8\%), afterwards applying a drop on carbon-coated copper or nickel (CVD deposits) mesh with holes (Lacey type $400 \mathrm{mesh}$ ) and evaporating the solvent at room temperature. To identify the chemical elements, energy-dispersive X-ray spectroscopy (EDX, RTEM model SN9577, $134 \mathrm{eV}, \mathrm{EDAX}, \mathrm{FEI}$, Hillsboro, OR, USA) spectra and selected area (electron) diffraction pattern were recorded. Atomic Force Microscopy (AFM) analysis of films was performed using a Veeco microscope (Veeco, Plainview, NY, USA).

\subsection{DFT Calculations}

The theoretical structures of complexes were optimised using density functional theory (DFT). All DFT calculations were performed using the Gaussian 16 (Wallingford, CT, USA) [47] available in PLGrid Infrastructure and the following sets of functionals and functional databases: B3LYP/6-31G, B3LYP/SDD $(\mathrm{Cu})+6-31 \mathrm{G}$, RBW91/LANL2DZ, RBW91/LANL2DZ, MN15/6-31G, M06/6-31G, M06/6-311G(d,p), and M06/LANL2DZ. The lowest energy of the system was obtained when using the hybrid functional of Truhlar and Zhao M06 [48] and 6-311G(d,p) basis set. GaussView 5.0 (Wallingford, CT, USA) was used to visualise optimised structures. 


\subsection{Software}

All graphical data were further processed with OriginPro 9.1 (Northampton, MA, USA). Diagrams of thermal and electron compounds decomposition were drawn using ChemDraw Ultra 12.0 (Mid-Cambridge, MA, USA). TA Universal Analysis (New Castle, DE, USA) was used to analyse thermograms. AFM images were prepared using the Gwyddion program (Brno, Czech Republic), while the roughness was determined using NanoScope Analysis (Bruker, Billerica, MA, USA). Grain size in the layers was determined by Image (LOCI, University of Wisconsin, Madison, WI, USA). To assign the decomposition products in VT IR experiments, the registered spectra were compared with the spectra of molecules in the gas phase collected in SpectraBase [49].

\subsection{Synthesis of $\left.\left.\left[\mathrm{Cu}_{2}\left(\mathrm{NH}_{2}(\mathrm{NH}=) \mathrm{CC}_{2} \mathrm{~F}_{5}\right)\right)_{2}\left(\mu-\mathrm{O}_{2} \mathrm{CR}_{\mathrm{F}}\right)_{4}\right]\right)((\mathbf{1})-(4))$}

Synthesis was carried out using Schlenk glassware and a glove box in an argon atmosphere. $\left[\mathrm{Cu}_{2}\left(\mu-\mathrm{O}_{2} \mathrm{CR}\right)_{4}\right]\left(0.5 \mathrm{mmol}, \mathrm{R}=\mathrm{CF}_{3}, \mathrm{C}_{2} \mathrm{~F}_{5}, \mathrm{C}_{3} \mathrm{~F}_{7}, \mathrm{C}_{4} \mathrm{~F}_{9}\right)$ was placed in a round-bottomed flask, and $20 \mathrm{~cm}^{3}$ of anhydrous acetonitrile was added, followed by the introduction of pentafluoropropylamidine (AMDH, $1 \mathrm{mmol})$. The resulting dark-blue solution was stirred for $24 \mathrm{~h}$. After this time, the solvent was removed under reduced pressure $\left(1.3 \times 10^{-3}-1.3 \times 10^{-4} \mathrm{mbar}\right)$. The obtained compounds were green-blue solids, stable in air. Yields ranged between $66 \%$ and $83 \%$. No crystals suitable for an X-ray structure determination were obtained.

$\left[\mathrm{Cu}_{2}(\mathrm{AMDH})_{2}\left(\mu-\mathrm{O}_{2} \mathrm{CCF}_{3}\right)_{4}\right]$ (1) $\mathrm{Cu}_{2} \mathrm{O}_{8} \mathrm{~N}_{4} \mathrm{H}_{6} \mathrm{C}_{14} \mathrm{~F}_{22}$ (calc./found) \% Cu 14.1/15.1, C 18.6/18.3; EI MS T = $396 \mathrm{~K}(\mathrm{~m} / \mathrm{z}, \mathrm{RI} \%)[\mathrm{AMDH}]^{+.}(162,36) ;[\mathrm{Cu}(\mathrm{AMDH})]^{+}(225,100)$; $\left[\mathrm{Cu}_{2}\left(\mathrm{O}_{2} \mathrm{CCF}_{3}\right)\right]^{+}(239,27) ;\left[\mathrm{Cu}(\mathrm{AMDH})_{2}\right]^{+}(387,71) ;\left[\mathrm{Cu}_{2}(\mathrm{AMD})_{2}\right]^{+}(448,29) ;\left[\mathrm{Cu}_{2}(\mathrm{AMDH})_{2}\right.$ $\left.\left(\mathrm{O}_{2} \mathrm{CCF}_{3}\right)_{3}\right]^{+}(789,67)$; IR $(3519,3380,3323,3258,3191,3009,1703,1670,1649,1597,1507$, $1443,1376,1334,1276,1189,1141,1029,974,926,846,795,772,727,686,647,637,618,599$, $\left.557,522,490,429,403 \mathrm{~cm}^{-1}\right)$.

[Cu $\left.\mathbf{C u}_{2}(\mathrm{AMDH})_{2}\left(\mu-\mathrm{O}_{2} \mathrm{CC}_{2} \mathrm{~F}_{5}\right)_{4}\right]$ (2) $\mathrm{Cu}_{2} \mathrm{O}_{8} \mathrm{~N}_{4} \mathrm{H}_{6} \mathrm{C}_{18} \mathrm{~F}_{30}$ (calc./found) \% Cu 11.5/11.5, C 19.6/18.4; EI MS T = $353 \mathrm{~K}(\mathrm{~m} / \mathrm{z}, \mathrm{RI} \%)[\mathrm{AMDH}]^{+} \cdot(162,39),[\mathrm{Cu}(\mathrm{AMDH})]^{+}(225,23)$, $\left[\mathrm{Cu}_{2}\left(\mathrm{O}_{2} \mathrm{CC}_{2} \mathrm{~F}_{5}\right)\right]^{+}(289,5),\left[\mathrm{Cu}(\mathrm{AMDH})_{2}\right]^{+}(387,14),\left[\mathrm{Cu}_{2}(\mathrm{AMD})_{3}\right]^{+}(609,7),\left[\mathrm{Cu}_{2}(\mathrm{AMDH})_{2}\right.$ $\left.\left(\mathrm{O}_{2} \mathrm{CC}_{2} \mathrm{~F}_{5}\right)_{3}\right]^{+}(939,24)$; IR $(3573,3516,3390,3240,3194,2955,1707,1657,1603,1555,1510$, 1424, 1324, 1209, 1157, 1032, 974, 897, 822, 772, 737, 686, 650, 612, 589, 554, 544, 516, $\left.432 \mathrm{~cm}^{-1}\right)$.

$\left[\mathrm{Cu}_{2}(\mathrm{AMDH})_{2}\left(\mu-\mathrm{O}_{2} \mathrm{CC}_{3} \mathrm{~F}_{7}\right)_{4}\right]$ (3) $\mathrm{Cu}_{2} \mathrm{O}_{8} \mathrm{~N}_{4} \mathrm{H}_{6} \mathrm{C}_{22} \mathrm{~F}_{38}$ (calc. / found) \% $\mathrm{Cu} 9.8 / 10.4, \mathrm{C}$ 20.2/20.1; EI MS T $=383 \mathrm{~K}(\mathrm{~m} / \mathrm{z}, \mathrm{RI} \%)[\mathrm{AMDH}]^{+} .(162,13),[\mathrm{Cu}(\mathrm{AMDH})]^{+}(225,4)$, $\left[\mathrm{Cu}_{2}\left(\mathrm{O}_{2} \mathrm{CC}_{3} \mathrm{~F}_{7}\right)\right]^{+}(339,<1),\left[\mathrm{Cu}(\mathrm{AMDH})_{2}\right]^{+}(387,1),\left[\mathrm{Cu}_{2}(\mathrm{AMDH})\left(\mathrm{O}_{2} \mathrm{CC}_{3} \mathrm{~F}_{7}\right)\right]^{+}(501,1)$, $\left[\mathrm{Cu}_{2}(\mathrm{AMDH})_{2}\left(\mathrm{O}_{2} \mathrm{CC}_{3} \mathrm{~F}_{7}\right)_{3}\right]^{+}(1089,2) ; \mathrm{IR}(3516,3387,3317,3252,3198,3059,3012,1710$, 1675, 1606, 1504, 1411, 1337, 1270, 1209, 1183, 1166, 1119, 1083, 1029, 971, 936, 820, 772, 743, $\left.721,682,650,637,602,564,532,483,429 \mathrm{~cm}^{-1}\right)$.

$\left[\mathrm{Cu}_{2}(\mathrm{AMDH})_{2}\left(\mu-\mathrm{O}_{2} \mathrm{CC}_{4} \mathrm{~F}_{9}\right)_{4}\right]$ (4) $\mathrm{Cu}_{2} \mathrm{O}_{8} \mathrm{~N}_{4} \mathrm{H}_{6} \mathrm{C}_{26} \mathrm{~F}_{46}$ (calc. / found) \% $\mathrm{Cu}$ 8.5/8.6, C 20.8/21.3; EI MS T $=396 \mathrm{~K}(\mathrm{~m} / \mathrm{z}, \mathrm{RI} \%)$ [AMDH] $^{+} \cdot(162,23),[\mathrm{Cu}(\mathrm{AMDH})]^{+}(225,54)$, $\left[\mathrm{Cu}(\mathrm{AMDH})_{2}\right]^{+}(387,25),\left[\mathrm{Cu}_{2}\left(\mathrm{O}_{2} \mathrm{CC}_{4} \mathrm{~F}_{9}\right)\right]^{+}(389,21),\left[\mathrm{Cu}_{2}(\mathrm{AMDH})\left(\mathrm{O}_{2} \mathrm{CC}_{4} \mathrm{~F}_{9}\right)\right]^{+}(551,9)$, $\left[\mathrm{Cu}(\mathrm{AMDH})_{2}\left(\mathrm{O}_{2} \mathrm{CC}_{4} \mathrm{~F}_{9}\right)\right]^{+}(650,47),\left[\mathrm{Cu}_{2}(\mathrm{AMDH})_{2}\left(\mathrm{O}_{2} \mathrm{CC}_{4} \mathrm{~F}_{9}\right)_{3}\right]^{+}(1239,38) ; \mathrm{IR}(3525,3390$, 3294, 3202, 2970, 1704, 1672, 1608, 1577, 1502, 1413, 1353, 1330, 1202, 1160, 1132, 1061, 1032, $\left.974,936,913,884,874,817,772,743,714,679,650,612,554,528,426 \mathrm{~cm}^{-1}\right)$.

\section{Results and Discussion}

In the acetonitrile environment, two amidine molecules are coordinated by dinuclear copper(II) carboxylate and complexes of formula $\left[\mathrm{Cu}_{2}(\mathrm{AMDH})_{2}\left(\mu-\mathrm{O}_{2} \mathrm{CR}\right)_{4}\right]$, where $\mathrm{R}=$ $\mathrm{CF}_{3}, \mathrm{C}_{2} \mathrm{~F}_{5}, \mathrm{C}_{3} \mathrm{~F}_{7}, \mathrm{C}_{4} \mathrm{~F}_{9}$, were formed:

$$
\left[\mathrm{Cu}_{2}\left(\mu-\mathrm{O}_{2} \mathrm{CR}_{\mathrm{F}}\right)_{4}\right]+2 \mathrm{AMDH} \rightarrow\left[\mathrm{Cu}_{2}(\mathrm{AMDH})_{2}\left(\mu-\mathrm{O}_{2} \mathrm{CR}_{\mathrm{F}}\right)_{4}\right]
$$

The obtained compounds (1)-(4) were blue-green air-stable solids. 


\subsection{Infrared Spectra Analysis}

In the infrared spectra (Supplementary Materials, Figures S1-S4), characteristic bands for asymmetric stretching vibrations of the carboxylate group were found over the range of $1649-1675 \mathrm{~cm}^{-1}$ (Table 1, Figure 1). Moreover, the value for symmetric stretching vibration was observed over the range of $1411-1443 \mathrm{~cm}^{-1}$. The calculated parameter $\Delta v=v_{\mathrm{asCOO}}-$ $v_{\mathrm{SCOO}}$, which is used for proposing of carboxylate coordination mode, was $206 \mathrm{~cm}^{-1}$ for the compound $\left[\mathrm{Cu}_{2}(\mathrm{AMDH})_{2}\left(\mu-\mathrm{O}_{2} \mathbf{C C F}_{3}\right)_{4}\right] \mathbf{( 1 )}$, which was close to the $\Delta v_{(\mathrm{RCOONa})}$ value for sodium trifluoroacetate $\left(223 \mathrm{~cm}^{-1}\right)$. This suggests the bridging coordination mode of the carboxylate ligand. A similar relationship $\Delta v \cong \Delta v_{(\mathrm{RCOONa})}$ occurred for the next compounds (2)-(4) and the formation of the carboxylate bridges was proposed.

Table 1. Selected IR absorption bands $\left(\mathrm{cm}^{-1}\right)$ of the studied compounds.

\begin{tabular}{|c|c|c|c|c|c|c|c|}
\hline Compound & $v_{\text {asNH2 }}$ & $v_{=N H}$ & $\delta_{\mathrm{NH} 2}$ & $v_{\mathrm{N}=\mathrm{C}-\mathrm{N}}$ & $v_{\text {asCOO }}$ & $v_{\mathrm{sCOO}}$ & $\Delta_{\mathrm{COO}}$ \\
\hline$\left[\mathrm{Cu}_{2}(\mathrm{AMDH})_{2}\left(\mu-\mathrm{O}_{2} \mathrm{CCF}_{3}\right)_{4}\right](1)$ & 3380 & 3009 & 1597 & 1507 & 1649 & 1443 & 206 \\
\hline$\left[\mathrm{Cu}_{2}(\mathrm{AMDH})_{2}\left(\mu-\mathrm{O}_{2} \mathrm{CC}_{2} \mathrm{~F}_{5}\right)_{4}\right](2)$ & 3390 & 3240 & 1603 & 1510 & 1657 & 1418 & 239 \\
\hline$\left[\mathrm{Cu}_{2}(\mathrm{AMDH})_{2}\left(\mu-\mathrm{O}_{2} \mathrm{CC}_{3} \mathrm{~F}_{7}\right)_{4}\right]$ & 3387 & 3012 & 1606 & 1504 & 1675 & 1411 & 264 \\
\hline$\left[\mathrm{Cu}_{2}(\mathrm{AMDH})_{2}\left(\mu-\mathrm{O}_{2} \mathrm{CC}_{4} \mathrm{~F}_{9}\right)_{4}\right](4)$ & 3390 & 3202 & 1608 & 1502 & 1672 & 1413 & 259 \\
\hline $\mathrm{AMDH}$ & 3362 & 3130 & 1593 & 1450 & - & - & - \\
\hline
\end{tabular}

$\Delta v\left(\mathrm{CF}_{3} \mathrm{CO}_{2} \mathrm{Na}\right)=223 \mathrm{~cm}^{-1}, \Delta v\left(\mathrm{C}_{2} \mathrm{~F}_{5} \mathrm{CO}_{2} \mathrm{Na}\right)=268 \mathrm{~cm}^{-1}, \Delta v\left(\mathrm{C}_{\mathrm{n}} \mathrm{F}_{2 \mathrm{n}+1} \mathrm{CO}_{2} \mathrm{Na} ; \mathrm{n}=3-4\right)=272 \mathrm{~cm}^{-1}$.

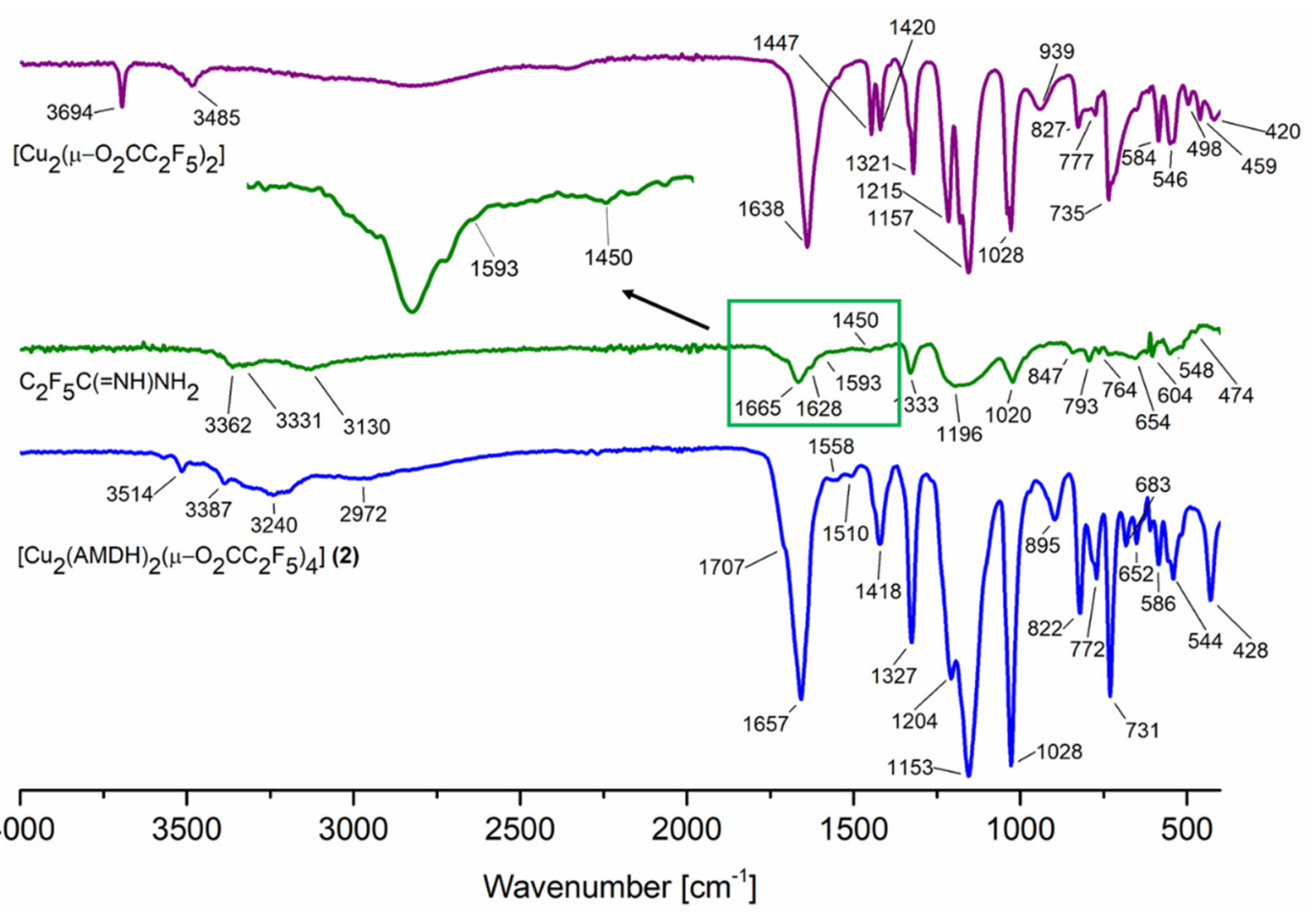

Figure 1. Infrared spectra for the reactants and the reaction product $\left[\mathrm{Cu}_{2}(\mathrm{AMDH})_{2}\left(\mu-\mathrm{O}_{2} \mathrm{CC}_{2} \mathrm{~F}_{5}\right)_{4}\right](2)$.

Bands characteristic of the amidine molecule were also observed in the spectrum: stretching vibration of the $\mathrm{C}=\mathrm{N}$ bond $\left(1703-1710 \mathrm{~cm}^{-1}\right)$, stretching vibration of a $=\mathrm{NH}$ group (3009-3240 $\mathrm{cm}^{-1}$ ), deformation vibrations of the $\mathrm{NH}_{2}$ amino group $\left(1597-1608 \mathrm{~cm}^{-1}\right.$ ), and stretching of $\mathrm{N}=\mathrm{C}-\mathrm{N}$ group $\left(1502-1510 \mathrm{~cm}^{-1}\right)$. The coordination shifts of the signals mentioned above (relative to the free ligand) were in the range of $39-46 \mathrm{~cm}^{-1}, 72-121 \mathrm{~cm}^{-1}$, $4-15 \mathrm{~cm}^{-1}$, and $52-60 \mathrm{~cm}^{-1}$, respectively (Table 1 ). The obtained results suggest the amidine coordination through the $=\mathrm{NH}$ group because the coordination shift for the vibrations of this group has the most significant value. 
Interestingly, the band characteristic for the stretching vibrations of the $=\mathrm{NH}$ group shifts towards lower values for compounds (1) and (3) with an odd number of carbon atoms in the carboxylate chain and higher values for compounds (2) and (4) with an even number of carbon atoms in the carboxylate chain. There is also a difference in the area of the stretching bonds of the $=\mathrm{NH}$ and $\mathrm{NH}_{2}$ groups (Figure 1 and Supplementary Materials, Figures S1-S4). It seems that, for compounds (1) and (3), the amidine arrangement in the structure is different than for compounds (2) and (4).

\subsection{DFT Calculations}

To confirm the way of amidine coordination, we decided to optimise the geometry using computational chemistry methods. For the complex $\left[\mathrm{Cu}_{2}(\mathrm{AMDH})_{2}\left(\mu-\mathrm{O}_{2} \mathrm{CCF}_{3}\right)_{4}\right]$ (1), calculations were started for the two structures in which the amidine coordination occurred through the $=\mathrm{NH}$ group (Figure $2 \mathrm{a}$ ) or $-\mathrm{NH}_{2}$ (Figure $2 \mathrm{~b}$ ). The calculations showed that the lower energy structure is that in which the amidine was bound via the $=\mathrm{NH}$ group (Figure 2). Therefore, in the case of complex (2), calculations were made only for the molecule with an amidine coordinated by the $=\mathrm{NH}$ bond (Figure 2c) owing to the size of the molecule, and thus the long computation time.

a)

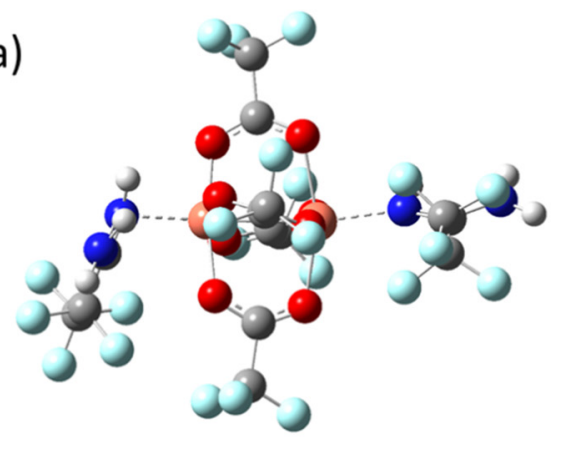

Total energy $=-6834.935151$

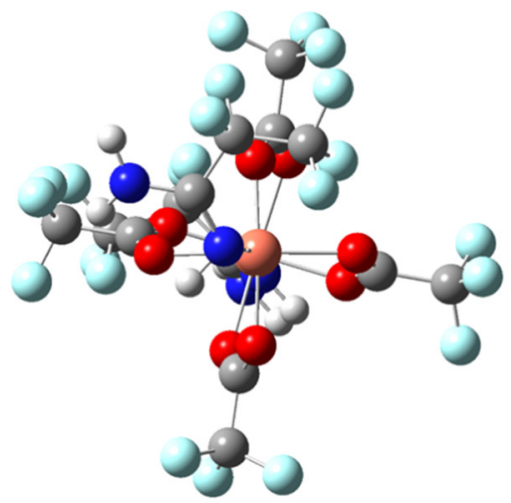

b)

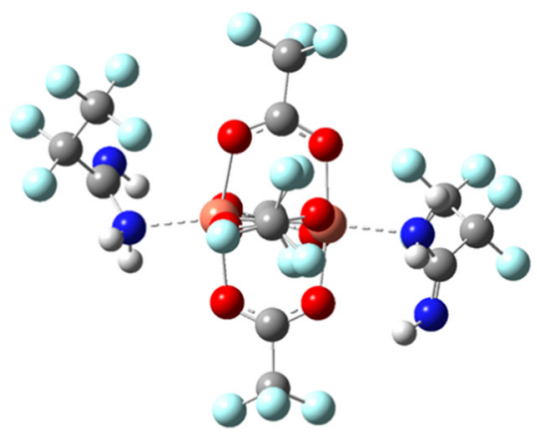

Total energy $=-6834.923570$ c)

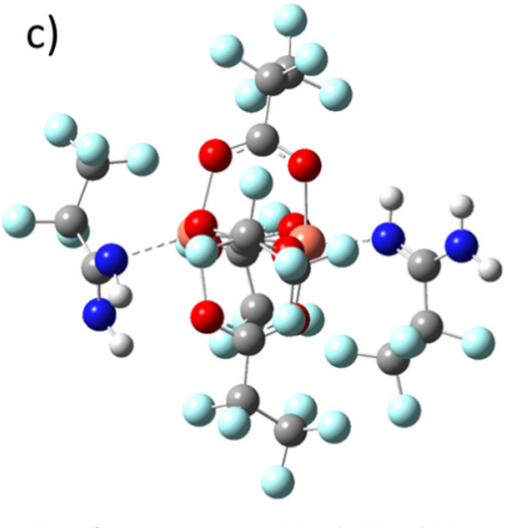

Total energy $=-7786.027402$

Figure 2. Optimised compounds structures by the density functional theory (DFT) M06/6-311G(d,p) method: (a) $\left[\mathrm{Cu}_{2}(\mathrm{AMDH})_{2}\left(\mu-\mathrm{O}_{2} \mathrm{CCF}_{3}\right)_{4}\right](\mathbf{1})$, $=\mathrm{NH}$ bonded; (b) $\left[\mathrm{Cu}_{2}(\mathrm{AMDH})_{2}\left(\mu-\mathrm{O}_{2} \mathrm{CCF}_{3}\right)_{4}\right]$ (1), $-\mathrm{NH}_{2}$ bonded; (c) $\left[\mathrm{Cu}_{2}(\mathrm{AMDH})_{2}\left(\mu-\mathrm{O}_{2} \mathrm{CC}_{2} \mathrm{~F}_{5}\right)_{4}\right](2),=\mathrm{NH}$ bonded.

It should be noted that the calculated structures are asymmetric, there is a distortion of the coordinated carboxylate, and the $\mathrm{Cu}-\mathrm{O}$ bonds are not equal (Figure 2). There are also differences in the spatial arrangement of amidines. The optimised structures confirm the different arrangement of the amidines in the structure for the compound (1) and (2). One of the amidine groups $\mathrm{H}_{2} \mathrm{~N}-\mathrm{C}=\mathrm{NH}$ is perpendicular to the copper atoms, while the other is parallel. 
Infrared spectra (Figure 3) were also calculated for the two alternative optimised structures to confirm the assigned bands in the experimental spectra of the complexes (Table 1). In the area of stretching bonds characteristic of the $-\mathrm{NH}_{2}$ and $=\mathrm{NH}$ groups for compound (1), in the case of amidine coordination by the $=\mathrm{NH}$ group (Figure 2a), a slight shift only in the position of the asymmetric stretching band of the $-\mathrm{NH}_{2}$ group vibrations in relation to the free ligand is calculated $\left(3716 \mathrm{~cm}^{-1}, \mathrm{AMDH} ; 3722 \mathrm{~cm}^{-1}, 3700 \mathrm{~cm}^{-1}\right.$, complex (1)). On the other hand, the band characteristic for the stretching vibrations of the $=\mathrm{NH}$ group shifts towards lower values $\left(3540 \mathrm{~cm}^{-1} \rightarrow 3498 \mathrm{~cm}^{-1}, 3485 \mathrm{~cm}^{-1}\right)$. In the case of compound (1) alternative structure (Figure $2 b$ ) in which the amidine was coordinated by the $-\mathrm{NH}_{2}$ group, a significant shift of the $\mathrm{NH}_{2}$ asymmetric stretching vibrations towards lower values was observed $\left(3716 \mathrm{~cm}^{-1} \rightarrow 3591 \mathrm{~cm}^{-1}\right)$. Comparing the theoretical and experimental infrared spectra for complex (1), it was confirmed that the amidine coordination occurs through the $=\mathrm{NH}$ group, because, in the experimental spectra, no significant shift of the band characteristic for the $-\mathrm{NH}_{2}$ group was detected (Table 1).

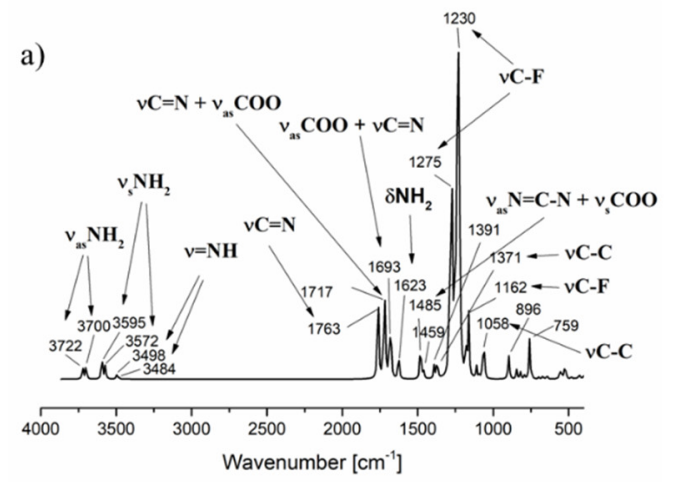

c)
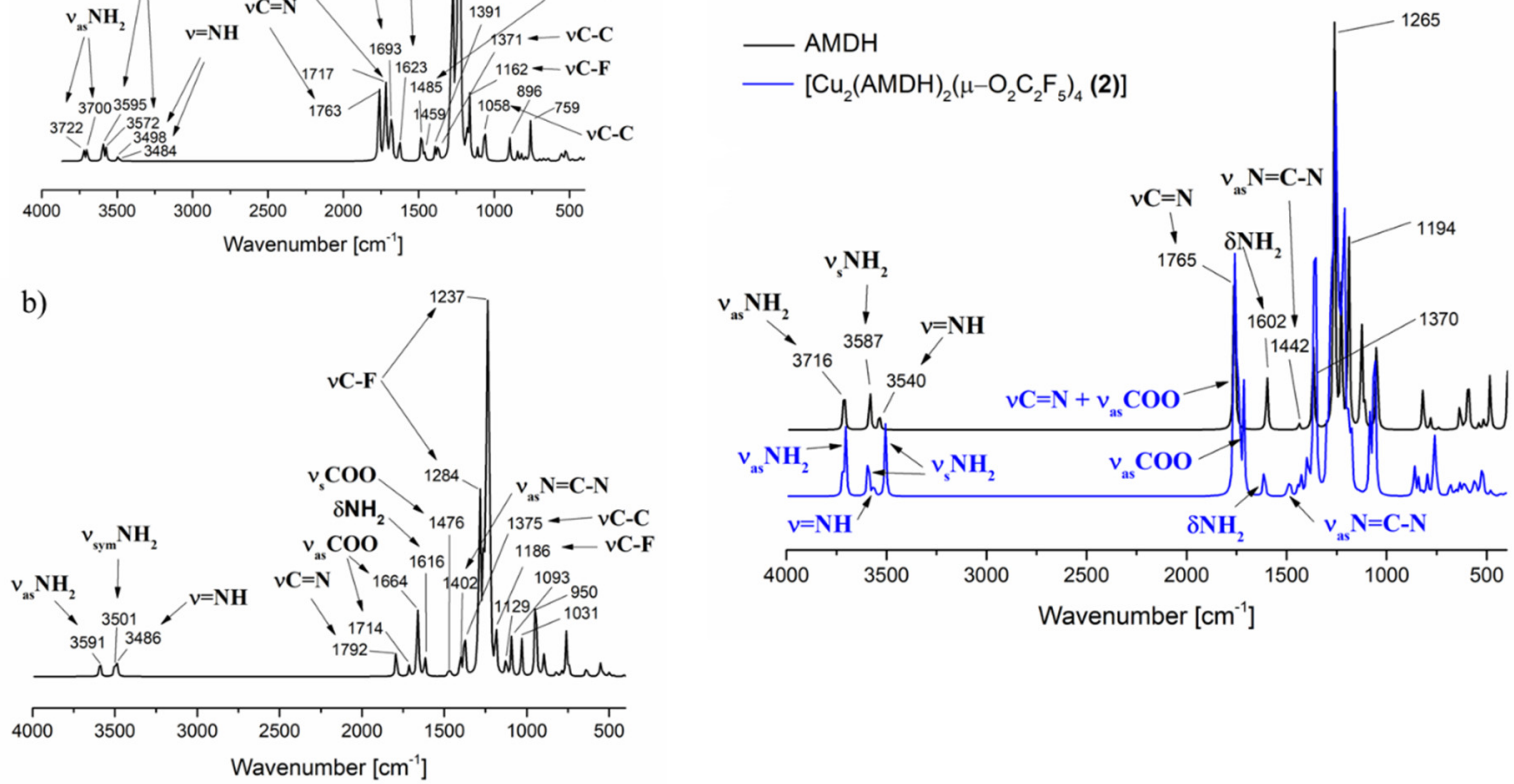

Figure 3. Theoretical infrared spectrum calculated by DFT M06/6-311G(d,p): (a) $\left[\mathrm{Cu}_{\mathbf{2}}(\mathbf{A M D H})_{\mathbf{2}}\left(\boldsymbol{\mu}-\mathrm{O}_{\mathbf{2}} \mathbf{C C F}_{3}\right)_{4}\right](\mathbf{1})$, $=\mathrm{NH}$ bonded amidine, $(\mathrm{b})\left[\mathrm{Cu}_{2}(\mathrm{AMDH})_{2}\left(\mu-\mathrm{O}_{2} \mathrm{CCF}_{3}\right)_{4}\right](\mathbf{1}),-\mathrm{NH}_{2}$ bonded amidine; $(\mathrm{c})\left[\mathrm{Cu}_{2}(\mathrm{AMDH})_{2}\left(\mu-\mathrm{O}_{2} \mathrm{CC}_{2} \mathrm{~F}_{5}\right)_{4}\right](\mathbf{1}),=\mathrm{NH}$ bonded (blue line) and AMDH (black line).

Interestingly, in the theoretical spectra, a difference was also observed in the shift of the stretching $=\mathrm{NH}$ band for complex (1) and (2) as in the experimental spectra. In compound (2), this band shifts towards higher values $\left(3540 \mathrm{~cm}^{-1} \rightarrow 3563 \mathrm{~cm}^{-1}\right)$. Moreover, in the theoretical spectrum for complex (1), there is a double set of bands for asymmetric and symmetric stretching vibrations of the $\mathrm{NH}_{2}$ group. However, in the case of (2), only for $-\mathrm{NH}_{2}$ symmetrical stretching vibrations, a double set of bands was observed. As a result, more bands in the region $>3000 \mathrm{~cm}^{-1}$ were observed in the spectrum for complex (1) than for complex (2), and it was also visible in the experimental spectra.

In the case of the stretching vibrations characteristic for the $\mathrm{C}=\mathrm{N}$ group, no coordination shift was observed in the theoretical spectra (Figure 3). It should be noted that the $v \mathrm{C}=\mathrm{N}$ bands overlap with the asymmetric stretching vibrations of the carboxylic groups. Because the theoretical spectra were calculated for molecules in the gas phase, the individ- 
ual bands are better separated. In the solid-phase spectrum (Figure 1), one band with the shoulder was observed, making it difficult to distinguish individual vibrations.

The theoretical spectra also confirmed the proposed assignment of bands characteristic for deformation vibrations of the $-\mathrm{NH}_{2}$ group and stretching vibrations of the $\mathrm{N}=\mathrm{C}-\mathrm{N}$ group (Section 3.1). The $v_{\text {as }} \mathrm{N}=\mathrm{C}-\mathrm{N}$ shifts more towards higher values $\left(1442 \mathrm{~cm}^{-1} \rightarrow\right.$ $\left.1485 \mathrm{~cm}^{-1}\right)$ than the $\delta \mathrm{NH}_{2}\left(1602 \mathrm{~cm}^{-1} \rightarrow 1623 \mathrm{~cm}^{-1}\right)$.

In conclusion, both the calculated energies and the band coordination shifts in the experimental and theoretical spectrum confirmed the coordination of the amidine by the $=\mathrm{NH}$ group.

\subsection{Thermal Analysis}

Thermal analysis was performed to examine the behavior of the complexes during heating under a nitrogen atmosphere and to determine the final decomposition temperature and the degradation product. Only for complex (1), two decomposition stages can be distinguished (Figure 4a). For the other compounds ((2)-(4)), the thermal decomposition consists of several overlapping steps particularly visible in the derivative graph (Figure $4 \mathrm{~b}$ ). This may be because, for complexes (2), (3), and (4), a small amount of residue was observed (Table 2) after the thermal analysis, which means that the complex can be partially evaporated under atmospheric pressure. However, under these conditions, in addition to evaporation, compound decomposition also occurs.

a)

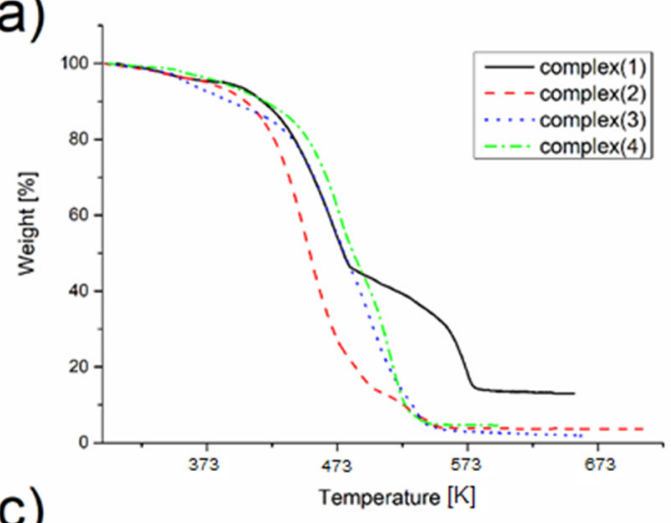

c)

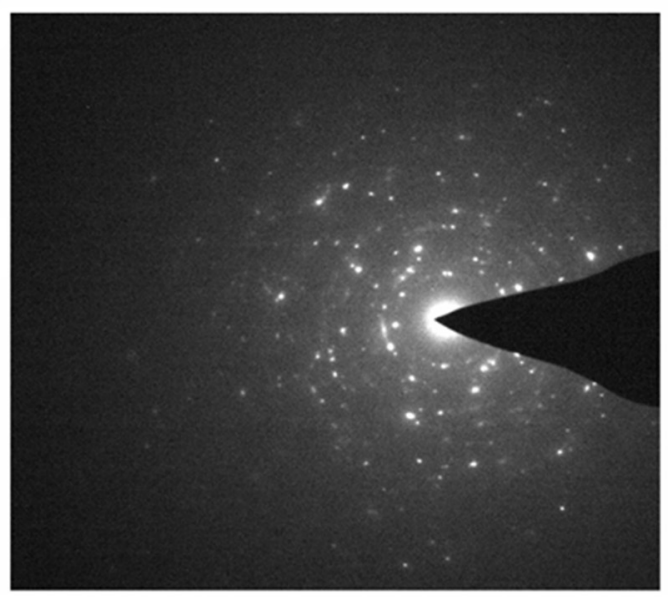

b)

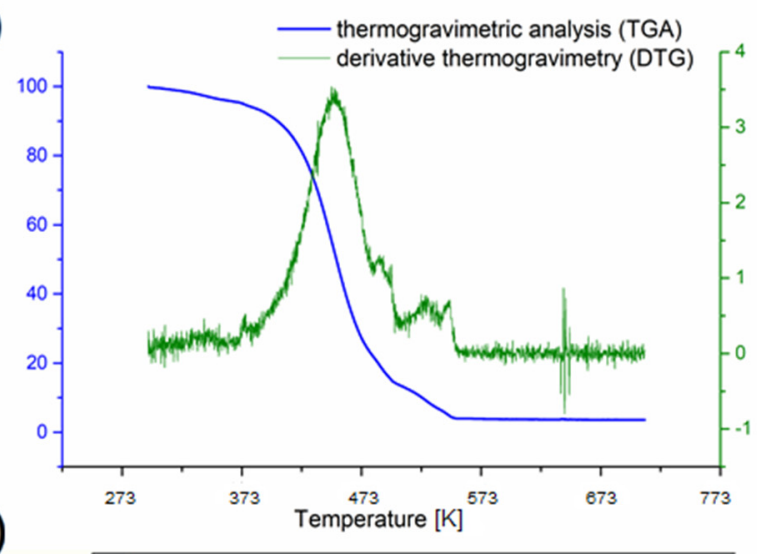

d)

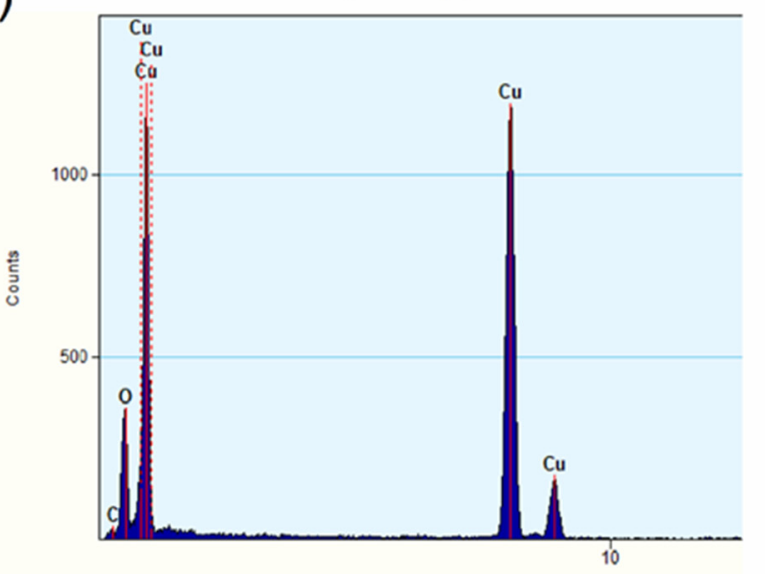

Figure 4. (a) Thermogravimetric analysis (TGA) for the complexes: (1), (2), (3), (4); (b) derivative thermogravimetry (DTG) and TGA for the complex (2) showing the complexity of the decomposition process; (c) transmission electron microscope (TEM) diffraction pattern for the residue from TGA of (2); (d) energy-dispersive X-ray spectroscopy (EDX) spectrum for the residue after TGA of (2). 
Table 2. Thermal analysis results.

\begin{tabular}{|c|c|c|c|c|c|}
\hline \multirow{2}{*}{ Complex } & \multicolumn{3}{|c|}{ Temperature (K) } & \multicolumn{2}{|c|}{ Residue $\mathrm{Cu}_{2} \mathrm{O}(\%)$} \\
\hline & $\mathbf{T}_{\mathbf{i}}$ & $\mathrm{T}_{\mathrm{m}}$ & $\mathrm{T}_{\mathrm{f}}$ & Found & Calc. \\
\hline \multirow{2}{*}[\mathrm{Cu}_{2}(\mathrm{AMDH})_{2}(\mu-\mathrm{O}_{2}\mathrm{CCF}_{3})_{4}]{$(\mathbf{1})$} & 391 & 471 & 492 & \multirow{2}{*}{13.0} & \multirow{2}{*}{15.8} \\
\hline & 544 & 573 & 586 & & \\
\hline$\left[\mathrm{Cu}_{2}(\mathrm{AMDH})_{2}\left(\mu-\mathrm{O}_{2} \mathrm{CC}_{2} \mathrm{~F}_{5}\right)_{4}\right](2)$ & 364 & 449 & 556 & 3.59 & 13.0 \\
\hline$\left[\mathrm{Cu}_{2}(\mathrm{AMDH})_{2}\left(\mu-\mathrm{O}_{2} \mathrm{CC}_{3} \mathrm{~F}_{7}\right)_{4}\right](3)$ & 337 & 499 & 551 & 1.96 & 11.0 \\
\hline$\left[\mathrm{Cu}_{2}(\mathrm{AMDH})_{2}\left(\mu-\mathrm{O}_{2} \mathrm{CC}_{4} \mathrm{~F}_{9}\right)_{4}\right](4)$ & 338 & 513 & 555 & 4.64 & 9.52 \\
\hline
\end{tabular}

$T_{i}$-initial temperature, $T_{m}$-maximum temperature, $T_{f}-$ final temperature.

To confirm the composition of the final product of thermal analysis, transmission electron microscope (TEM) was used owing to the small amount left in the crucible. TEM diffraction pattern and EDX spectra (Figure 4c,d) revealed that the decomposition product under the conditions of thermal analysis (atmospheric pressure, nitrogen atmosphere) is copper(I) oxide.

The temperature of the decomposition process onset changed over the range of $337-391 \mathrm{~K}$, and the temperature of the final product formation varied from $551 \mathrm{~K}$ (3) to $586 \mathrm{~K}$ (1) (Table 2). For comparison, in the case of complexes mentioned in the Introduction with amines $\left[\mathrm{Cu}_{2}\left({ }^{\mathrm{t}} \mathrm{BuNH}_{2}\right)_{2}\left(\mu-\mathrm{O}_{2} \mathrm{CR}_{\mathrm{F}}\right)_{4}\right]$, these values were $318-396 \mathrm{~K}$ and $458-668 \mathrm{~K}$, respectively. Interestingly, in the case of complexes with $\mathrm{CF}_{3}$ and $\mathrm{C}_{2} \mathrm{~F}_{5}$ substituents, lower $T_{i}$ and $T_{f}$ temperatures were observed for the complexes with tert-butylamine in the axial position. However, for the $\mathrm{C}_{3} \mathrm{~F}_{7}$ and $\mathrm{C}_{4} \mathrm{~F}_{9}$ chains, lower temperatures were registered for the complexes with amidine [41].

\subsection{Mass Spectra Analysis}

Mass spectra (EI-MS) of the studied compounds were registered between 303 and $623 \mathrm{~K}$ and applied to determine the composition of the complex and identify metallated fragments. The benefit of this approach is that the compound is first evaporated and then exposed to electrons $(70 \mathrm{eV})$.

For all compounds, the pseudomolecular ion of the $\left[\mathrm{Cu}_{2}(\mathrm{AMDH})_{2}\left(\mathrm{O}_{2} \mathrm{CR}_{\mathrm{F}}\right)_{3}\right]^{+}$formula, where $R_{F}=C_{n} F_{2 n+1}, n=1-4$, formed by the detachment of one carboxylate ligand, was visible in EI MS spectra (Table 3 and Tables S1-S3). Pseudomolecular ions of this type were previously observed for $\left[\mathrm{Cu}_{2}\left({ }^{\mathrm{t}} \mathrm{BuNH}_{2}\right)_{2}\left(\mu-\mathrm{O}_{2} \mathrm{CR}_{\mathrm{F}}\right)_{4}\right]$ complexes with tert-butylamine in the axial position [41]. For compounds (1) and (2), this ion is already present at low temperatures: $313 \mathrm{~K}(\mathrm{RI}=4 \%)$ and $327 \mathrm{~K}(\mathrm{RI}=8 \%)$, respectively. The $\left[\mathrm{Cu}_{2}(\mathrm{AMDH})_{2}\left(\mathrm{O}_{2} \mathrm{CR}_{\mathrm{F}}\right)_{3}\right]^{+}$ion reaches its highest intensity over the temperature range of $353-396 \mathrm{~K}$ with only $2 \%$ RI for compound (3) and $67 \%$ RI for compound (1). The low intensity of the pseudomolecular ion for compound (3) may result from its high sensitivity to the electron beam, which caused its rapid decomposition. This is also evidenced by the high intensity of the $\left[\mathrm{Cu}_{2} \mathrm{~F}\right]^{+}$ion, which is the end product of the decomposition (Figure 5) and for the compound (3) reached $97 \% \mathrm{RI}$ at $550 \mathrm{~K}$ (Table S2). Generally, there are also other detected dinuclear and mononuclear metallated fragments containing both ligands, such as $\left[\mathrm{Cu}_{2}(\mathrm{AMDH})_{2}\left(\mathrm{O}_{2} \mathrm{CR}_{\mathrm{F}}\right)_{2}\right]^{+},\left[\mathrm{Cu}_{2}(\mathrm{AMDH})\left(\mathrm{O}_{2} \mathrm{CR}_{\mathrm{F}}\right)_{3}\right]^{+},\left[\mathrm{Cu}(\mathrm{AMDH})_{2}\left(\mathrm{O}_{2} \mathrm{CR}_{\mathrm{F}}\right)\right]^{+}$, and $\left[\mathrm{Cu}(\mathrm{AMDH})\left(\mathrm{O}_{2} \mathrm{CR}_{\mathrm{F}}\right)\right]^{+}$. This fact confirms the coordination of the entire amidine molecule to the perfluorinated copper(II) carboxylate. Moreover, the intact molecule of the tested compound passes into the gas phase. Interestingly, ions containing $\mathrm{Cu}(\mathrm{I})$ detection, such as $\left[\mathrm{Cu}_{2}(\mathrm{AMDH})_{2}\left(\mathrm{O}_{2} \mathrm{CR}_{\mathrm{F}}\right)\right]^{+}$and $\left[\mathrm{Cu}_{2}(\mathrm{AMDH})\left(\mathrm{O}_{2} \mathrm{CR}_{\mathrm{F}}\right)\right]^{+}$, suggest $\mathrm{Cu}(\mathrm{II})$ reduction during the thermolysis of the compounds. In the case of compounds (3) and (4), even trinuclear and tetranuclear ions $\left[\mathrm{Cu}_{3}(\mathrm{AMDH})\left(\mathrm{O}_{2} \mathrm{CC}_{4} \mathrm{~F}_{9}\right)_{5}\right]^{+}\left(\mathrm{RI}_{\max }=3,428 \mathrm{~K}\right),\left[\mathrm{Cu}_{3}(\mathrm{AMDH})\left(\mathrm{O}_{2} \mathrm{CR}_{\mathrm{F}}\right)_{4}\right]^{+}$ $\left(\mathrm{RI}_{\max }=17,460 \mathrm{~K}\right)$, and $\left[\mathrm{Cu}_{4}\left(\mathrm{NH}_{2}\right)_{2}(\mathrm{AMDH})(\mathrm{AMD})_{2}\left(\mathrm{O}_{2} \mathrm{CC}_{4} \mathrm{~F}_{9}\right)_{2}\right]^{+}\left(\mathrm{RI}_{\max }=4,460 \mathrm{~K}\right)$ were observed. This may indicate the polymeric structure of these complexes. 
Table 3. Mass spectrometry with electron ionisation (EI MS) results for $\left[\mathrm{Cu}_{2}(\mathrm{AMDH})_{2}\left(\mu-\mathrm{O}_{2} \mathrm{C}_{2} \mathrm{~F}_{5}\right)_{4}\right](\mathbf{2})$.

\begin{tabular}{|c|c|c|c|c|c|c|}
\hline \multirow{2}{*}{ Fragments } & \multirow{2}{*}{$\mathbf{m} / \mathbf{z}$} & \multicolumn{5}{|c|}{ Temperature [K] } \\
\hline & & 327 & 353 & 398 & 433 & 529 \\
\hline$\left[\mathrm{Cu}_{2}(\mathrm{AMDH})_{2}\left(\mathrm{O}_{2} \mathrm{CC}_{2} \mathrm{~F}_{5}\right)_{3}\right]^{+}$ & 939 & 8 & 24 & 7 & 3 & - \\
\hline$\left[\mathrm{Cu}_{2}(\mathrm{AMDH})(\mathrm{HN}=\mathrm{C}=\mathrm{NH})\left(\mathrm{O}_{2} \mathrm{CC}_{2} \mathrm{~F}_{5}\right)_{3}\right]^{+}$ & 819 & $<1$ & 2 & $<1$ & - & - \\
\hline$\left[\mathrm{Cu}_{2}(\mathrm{AMDH})_{2}\left(\mathrm{O}_{2} \mathrm{CC}_{2} \mathrm{~F}_{5}\right)_{2}\right]^{+}$ & 776 & 1 & 3 & 4 & 7 & - \\
\hline$\left[\mathrm{Cu}_{2}(\mathrm{AMD})_{2}\left(\mathrm{O}_{2} \mathrm{CC}_{2} \mathrm{~F}_{5}\right)_{2}\right]^{+}$ & 774 & $<1$ & 1 & 1 & - & - \\
\hline$\left[\mathrm{Cu}_{2}(\mathrm{AMD})_{3}\right]^{+}$ & 609 & 2 & 7 & 2 & 1 & - \\
\hline$\left[\mathrm{Cu}(\mathrm{AMDH})(\mathrm{AMD})\left(\mathrm{O}_{2} \mathrm{CC}_{2} \mathrm{~F}_{5}\right)\right]^{+}$ & 549 & 9 & 30 & 10 & 4 & - \\
\hline$\left[\mathrm{Cu}_{2}\left(\mathrm{O}_{2} \mathrm{CC}_{2} \mathrm{~F}_{5}\right)_{2}\right]^{+}$ & 452 & 1 & 4 & 3 & 3 & 18 \\
\hline$\left[\mathrm{Cu}_{2}(\mathrm{AMDH})\left(\mathrm{O}_{2} \mathrm{CC}_{2} \mathrm{~F}_{5}\right)\right]^{+}$ & 451 & 2 & 5 & 3 & 4 & $<1$ \\
\hline$\left[\mathrm{Cu}_{2}(\mathrm{AMD})\left(\mathrm{O}_{2} \mathrm{CC}_{2} \mathrm{~F}_{5}\right)\right]^{+}$ & 450 & 2 & 4 & 4 & 8 & $<1$ \\
\hline$\left[\mathrm{Cu}(\mathrm{AMDH})_{2}\right]^{+}$ & 387 & 4 & 14 & 9 & - & - \\
\hline$\left[\mathrm{Cu}(\mathrm{AMD})_{2}\right]^{+}$ & 385 & 6 & 18 & 7 & - & - \\
\hline$\left[\mathrm{Cu}_{2}\left(\mathrm{O}_{2} \mathrm{CC}_{2} \mathrm{~F}_{5}\right)\right]^{+}$ & 289 & 2 & 5 & 5 & 10 & 50 \\
\hline$[\mathrm{Cu}(\mathrm{AMDH})(\mathrm{HN}=\mathrm{C}=\mathrm{NH})]^{+}$ & 267 & 4 & 10 & 6 & 3 & - \\
\hline$[\mathrm{Cu}(\mathrm{AMD})(\mathrm{HN}=\mathrm{C}=\mathrm{NH})]^{+}$ & 266 & 1 & 3 & 1 & 1 & - \\
\hline$[\mathrm{AMDH}]^{+}$ & 162 & 9 & 39 & 7 & 8 & - \\
\hline$\left[\mathrm{NH}_{2} \mathrm{CC}_{2} \mathrm{~F}_{5}\right]^{+}$ & 147 & 9 & 34 & 11 & 23 & 12 \\
\hline$\left[\mathrm{Cu}_{2} \mathrm{~F}\right]^{+}$ & 145 & - & $<1$ & 1 & 2 & 13 \\
\hline$\left[\mathrm{C}_{2} \mathrm{~F}_{4} \mathrm{CN}\right]^{+}$ & 126 & 62 & 100 & 66 & 75 & 51 \\
\hline$\left[\mathrm{C}_{2} \mathrm{~F}_{5}\right]^{+}$ & 119 & 86 & 1 & 100 & 1 & 100 \\
\hline$\left[\mathrm{CF}_{2} \mathrm{CN}\right]^{+}$ & 76 & 80 & 1 & 85 & 100 & 67 \\
\hline$[\mathrm{Cu}]^{+}$ & 63 & - & 1 & 2 & 2 & 9 \\
\hline$\left[\mathrm{CO}_{2} \mathrm{H}\right]^{+}$ & 45 & 40 & 1 & 45 & 90 & 24 \\
\hline$\left[\mathrm{CO}_{2}\right]^{+}$ & 44 & 100 & 75 & 76 & 90 & 1 \\
\hline$[\mathrm{HN}=\mathrm{C}=\mathrm{NH}]^{+}$ & 42 & 5 & 7 & 2 & 2 & 2 \\
\hline$\left[\mathrm{F}_{2}\right]^{+}$ & 38 & 9 & 3 & 3 & 2 & 1 \\
\hline
\end{tabular}

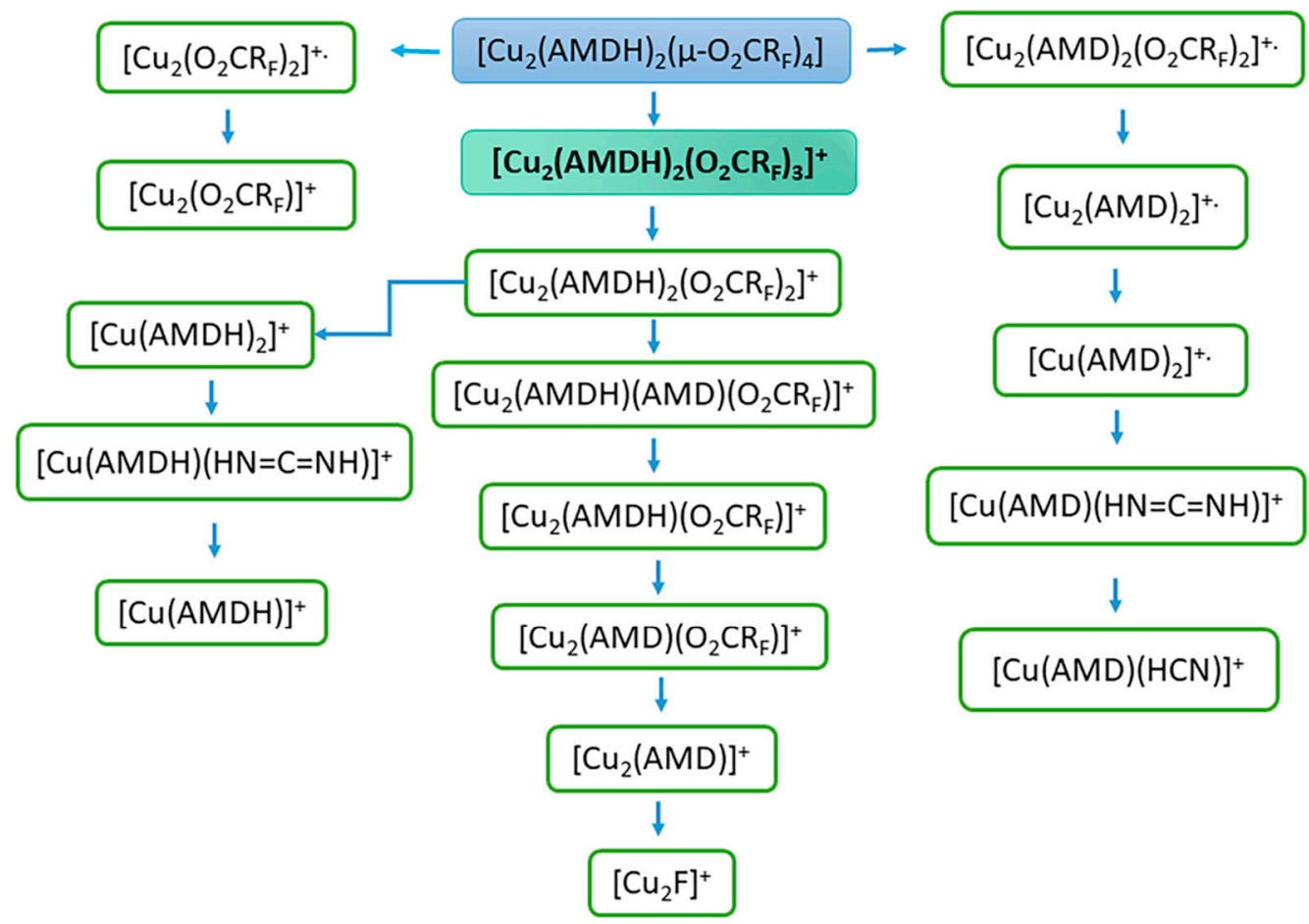

Figure 5. Fragmentation scheme for metallated fragments of $\left[\mathrm{Cu}_{2}(\mathrm{AMDH})_{2}\left(\mu-\mathrm{O}_{2} \mathrm{CR}_{\mathrm{F}}\right)_{4}\right]$.

Ions containing deprotonated amidine (i.e., amidinate) having the following composition: $\left[\mathrm{Cu}_{2}(\mathrm{AMD})\left(\mathrm{O}_{2} \mathrm{CR}_{\mathrm{F}}\right)_{3}\right]^{+}$, $\left[\mathrm{Cu}_{2}(\mathrm{AMD})_{2}\left(\mathrm{O}_{2} \mathrm{CR}_{\mathrm{F}}\right)_{2}\right]^{+}$, $\left[\mathrm{Cu}_{2}(\mathrm{AMD})_{2}\left(\mathrm{O}_{2} \mathrm{CR} \mathrm{F}\right)-\mathrm{H}\right]^{+},\left[\mathrm{Cu}_{2}(\mathrm{AMD})\right.$ $\left.\left(\mathrm{O}_{2} \mathrm{CR}_{\mathrm{F}}\right)_{2}-\mathrm{H}\right]^{+}$, and $\left[\mathrm{Cu}_{2}(\mathrm{I}, \mathrm{II})(\mathrm{AMD})\left(\mathrm{O}_{2} \mathrm{CR}_{\mathrm{F}}\right)\right]^{+} /\left[\mathrm{Cu}_{2}(\mathrm{I})(\mathrm{AMD})\left(\mathrm{O}_{2} \mathrm{CR}_{\mathrm{F}}\right)\right]^{+\cdot}$ (the highest in- 
tensities they achieved in the temperature range of 398-486 K) were detected in the spectra. The obtained results exhibited the deprotonation of the coordinated amidine ligand during heating (vide infra, Section 3.5) under measurement conditions.

It is also worth noting the formation of ions containing coordinated ligands that were formed as a result of amidine decomposition, for example, $\left[\mathrm{Cu}_{2}\left(\mathrm{NH}_{2}\right)(\mathrm{AMD})_{2}\left(\mathrm{O}_{2} \mathrm{CCF}_{3}\right)\right]^{+}$, $[\mathrm{Cu}(\mathrm{AMDH})(\mathrm{HN}=\mathrm{C}=\mathrm{NH})]^{+}$, and $[\mathrm{Cu}(\mathrm{AMD})(\mathrm{HCN})]^{+}$. This may indicate that the formed $\mathrm{Cu}-\mathrm{N}$ bond is strong. Therefore, the bonds in the ligand molecule were broken, and the amidine/amidinate was not completely detached.

Interestingly, at low temperatures (313-371 K), copper(I) and copper(II) fragments containing only $\mathrm{N}$-donor ligands are also formed, such as $\left[\mathrm{Cu}_{2}(\mathrm{AMD})_{3}\right]^{+}\left[\mathrm{Cu}_{2}(\mathrm{AMD})_{2}\right]^{+}$, $\left[\mathrm{Cu}(\mathrm{AMDH})_{2}\right]^{+},\left[\mathrm{Cu}(\mathrm{AMD})_{2}\right]^{+}$, and $[\mathrm{Cu}(\mathrm{AMDH})]^{+}$. Moreover, in the case of compound (1), the $[\mathrm{Cu}(\mathrm{AMDH})]^{+\cdot}$ fragment reaches $100 \% \mathrm{RI}$ at $393 \mathrm{~K}$, while for compound (4), it achieves $99 \% \mathrm{RI}$ at $428 \mathrm{~K}$. On the other hand, ions containing only the carboxylate ligand reach their highest intensity at higher temperatures. In the case of $\left[\mathrm{Cu}_{2}\left(\mathrm{O}_{2} \mathrm{CR}_{\mathrm{F}}\right)_{2}\right]^{+}$. ion, the relative intensity varies from 18 to $96 \%$ in the temperature range of $505-550 \mathrm{~K}$ (Table 3 and Tables S1-S3). In turn, the ion $\left[\mathrm{Cu}_{2}\left(\mathrm{O}_{2} \mathrm{CR}_{\mathrm{F}}\right)\right]^{+}$reaches the highest intensity $(50-75 \% \mathrm{RI})$ over the $428-538 \mathrm{~K}$ temperature range. The obtained results may indicate that the metal species with the amidinate ligand are more volatile than those with the carboxylate.

At the beginning of heating, fragments such as $[\mathrm{AMDH}]^{+},\left[\mathrm{C}_{2} \mathrm{~F}_{5}\right]^{+},\left[\mathrm{CO}_{2}\right]^{+},\left[\mathrm{CO}_{2} \mathrm{H}\right]^{+}$, $[\mathrm{HN}=\mathrm{C}=\mathrm{NH}]^{+}$, and $\left[\mathrm{F}_{2}\right]^{+}$. appear, which indicate the degradation of the compounds. However, it is difficult to distinguish which ions result from thermal decomposition and which are the result of interactions with electrons. The appearance of carbodiimide $[\mathrm{HN}=\mathrm{C}=\mathrm{NH}]^{+}$ suggests carbodiimide detachment as one of the mechanisms of degradation [50]. However, there is also release of amidine as a decomposition factor. The presence of $\left[\mathrm{CO}_{2} \mathrm{H}\right]^{+}$is evidence of amidine deprotonation by carboxylate and the formation of carboxylic acid and amidinate.

$\left[\mathrm{Cu}_{2} \mathrm{~F}\right]^{+}$fragment was also detected in MS EI spectra for all studied compounds. It reaches an intensity of 13 to $97 \%$ RI at high temperatures (505-550 K) (Table 3 and Tables S1-S3). In the case of compound (2), $[\mathrm{Cu}]^{+}$ion was also observed. The formation of this type of ions indicates that electrons can cause the decomposition of compounds into copper(I) fluoride or copper (vide infra). This is a desirable property for the potential precursors used in the FEBID method.

\subsection{Variable Temperature Infrared Spectroscopy (VT IR)}

To examine the composition of the gas phase formed during the heating of the complexes, variable temperature infrared spectroscopy was carried out. The measurement conditions are similar to the deposition parameters during the CVD experiments.

In the first step of decomposition (stage I), the band characteristics of the amidine molecule $\left(3565 \mathrm{~cm}^{-1} ; v_{\mathrm{as}} \mathrm{NH}_{2}, 3527 \mathrm{~cm}^{-1} ; v_{\mathrm{s}} \mathrm{NH}_{2}, 3446 \mathrm{~cm}^{-1} ; v=\mathrm{NH}, 1776 \mathrm{~cm}^{-1} ; v \mathrm{CN}\right.$, $1590 \mathrm{~cm}^{-1}, \delta \mathrm{NH}$ ) were observed for compounds (1), (3), and (4) in the temperature range of 333-413 K (Figures S1-S3). In the case of compound (2), in addition to the bands mentioned above, there are the following observed signals: $3191 \mathrm{~cm}^{-1}\left(v \mathrm{NH}_{2}\right), 1734 \mathrm{~cm}^{-1}(\nu \mathrm{CN}+$ $\left.v_{\mathrm{as}} \mathrm{COO}\right)$, and $1683 \mathrm{~cm}^{-1}\left(\mathrm{v}_{\mathrm{as}} \mathrm{COO}\right)$ characteristic for complex (2), and signals $3515 \mathrm{~cm}^{-1}$ $\left(v \mathrm{NH}_{2}\right)$ and $1705 \mathrm{~cm}^{-1}(v \mathrm{CN})$ assigned to the coordinated amidinate $(\mathrm{Cu}-\mathrm{AMD})$ species. It is difficult to propose a mode of amidinate coordination owing to the lack of spectroscopic data in the literature for copper compounds with perfluorinated AMD. These species occur in the gas phase over the temperature range of 353-533 K (Figure 6 and Figure S8). 


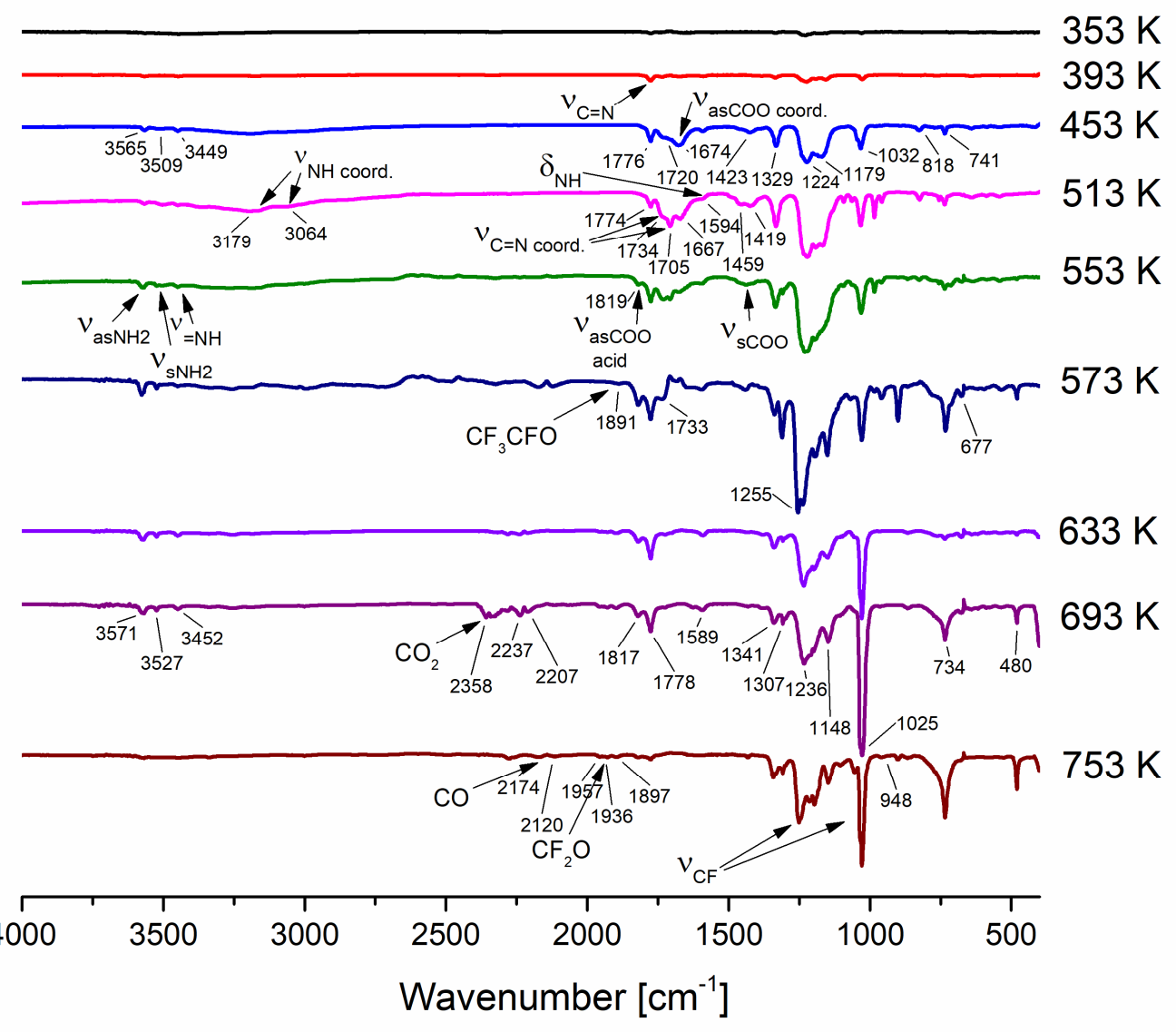

Figure 6. VT IR spectra of $\left[\mathrm{Cu}_{2}(\mathrm{AMDH})_{2}\left(\mu-\mathrm{O}_{2} \mathrm{CC}_{2} \mathrm{~F}_{5}\right)_{4}\right](2)$ in the temperature range of 353-753 K.

Similarly, the second decomposition step (stage II) is comparable for compounds (1), (3), and (4). HAMD's characteristic bands are still being observed. The entire molecules of complexes (1), (3), and (4) are also present at this stage in the temperature range of 433-453 K (1), (3), and 433-473 K (4). Moreover, in the gas phase, $\mathrm{Cu}-\mathrm{AMD}$ species occur (Figures S5-S7). In the case of complex (2), in addition to the molecules mentioned above, signals, $1824 \mathrm{~cm}^{-1}\left(v_{\mathrm{as}} \mathrm{COO}\right)$ and $1440 \mathrm{~cm}^{-1}\left(v_{\mathrm{s}} \mathrm{COO}\right)$ bands were observed in the gas phase at $553 \mathrm{~K}$, characteristic for carboxylic acid (Figure 6) [51].

At higher temperatures, there are more differences in the way compounds are decomposed. Generally, compounds (1), (3), and (4) have more decomposition stages than complex (2).

For compound (2) in the temperature range of 573-653 K (stage III), there are characteristic bands for $\mathrm{Cu}-\mathrm{AMD}$ species, $\mathrm{Cu}_{2}\left(\mathrm{O}_{2} \mathrm{CR}_{\mathrm{F}}\right)_{4}\left(1651 \mathrm{~cm}^{-1} ; v_{\mathrm{as}} \mathrm{COO}\right)$ [42], HAMD, $\mathrm{R}_{\mathrm{F}} \mathrm{COOH}$ [51], $\mathrm{CF}_{3} \mathrm{CFO}\left(1889 \mathrm{~cm}^{-1}, 736 \mathrm{~cm}^{-1}, 676 \mathrm{~cm}^{-1}\right)$ [52], $\mathrm{CF}_{2} \mathrm{O}\left(1957 \mathrm{~cm}^{-1}, 1936\right.$ $\left.\mathrm{cm}^{-1}\right)$ [52], $\mathrm{CO}_{2}\left(2322 \mathrm{~cm}^{-1}\right)$ [53], and $\mathrm{CO}\left(2174 \mathrm{~cm}^{-1}, 2126 \mathrm{~cm}^{-1}\right)$ [54]. In turn, in the $673-753 \mathrm{~K}$ temperature range (stage $I V$ ), there are no more metalled species. Only decomposition products mentioned above such as $\mathrm{HAMD}, \mathrm{R}_{\mathrm{F}} \mathrm{COOH}, \mathrm{CF}_{3} \mathrm{CFO}, \mathrm{CF}_{2} \mathrm{O}, \mathrm{CO}_{2}$, and CO occurred (Figure 6).

In the case of compound (1) in the third step of decomposition (stage III), there are characteristic bands for the entire complex (1) molecules, Cu-AMD, HAMD, and the carboxylic acid, at the temperature range of $473-533 \mathrm{~K}$. The fourth stage of decomposition (stage IV) occurs in the temperature range of 553-593 K. The gas-phase contained the following species: $\mathrm{Cu}-\mathrm{AMD}, \mathrm{Cu}_{2}\left(\mathrm{O}_{2} \mathrm{CCF}_{3}\right)_{4}, \mathrm{HAMD}, \mathrm{CF}_{3} \mathrm{COOH}$ [55], $\mathrm{CF}_{3} \mathrm{CFO}, \mathrm{CO}_{2}$, and $\mathrm{CO}$. The next stage (stage $V, 613-633 \mathrm{~K}$ ) differs from the previous one by the lack of metal carriers. In the last tested temperature range (stage VI, 653-753 K) in the gas phase, HAMD, $\mathrm{CF}_{3} \mathrm{COOH}, \mathrm{CO}_{2}$, and $\mathrm{CO}$ (Figure S5) were detected. 
Compared with compound (1), in the third stage of complex (3) decomposition (stage III, 473-493 K), an additional band $\left(2272 \mathrm{~cm}^{-1}\right)$ was observed in the VT IR spectra. This band is characteristic of a gaseous $\mathrm{C}_{2} \mathrm{~F}_{5} \mathrm{CN}$. [56] At $513 \mathrm{~K}$ (stage IV), the gas phase consists of the following species: complex (3), $\mathrm{Cu}$-AMD, HAMD, $\mathrm{C}_{3} \mathrm{~F}_{7} \mathrm{COOH}$ [57], $\mathrm{C}_{2} \mathrm{~F}_{5} \mathrm{CN}$, and $\mathrm{CO}_{2}$. In turn, in the temperature range of $533-553 \mathrm{~K}$ (stage $V$ ), in addition to the aforementioned degradation products, $\mathrm{CO}$ molecule was detected. In the next step of decomposition (stage VI, 573-593 K), copper(II) perfluorobutyrate $\left(1658 \mathrm{~cm}^{-1}\right)$ was the only metal carrier. Additionally, the bands $1795 \mathrm{~cm}^{-1}$ (C=C stretching vibrations) and $1396 \mathrm{~cm}^{-1}$ (asymmetric $\mathrm{C}$-F stretching mode in the $\mathrm{CF}_{3}$ group) were recorded in the VT IR spectra characteristic of the $\mathrm{CF}_{2}=\mathrm{CF}-\mathrm{CF}_{3}$ molecule. [58] $\mathrm{R}_{\mathrm{F}} \mathrm{COOH}, \mathrm{CF}_{3} \mathrm{CFO}, \mathrm{C}_{2} \mathrm{~F}_{5} \mathrm{CN}, \mathrm{CO}_{2}$, and $\mathrm{CO}$ were also observed in the gas phase at these temperatures. With increasing temperature (613-653 K, stage VI), the composition of the gas phase changes slightly compared with stage $V$, and there are no $\mathrm{CF}_{3} \mathrm{CFO}$ molecules (Figure $\mathrm{S6}$ ).

In the case of compound (4), the molecules $\mathrm{Cu}-\mathrm{AMD}, \mathrm{HAMD}$, and $\mathrm{C}_{4} \mathrm{~F}_{9} \mathrm{COOH}$ occur in the third phase of degradation (stage III, 493-533 K). In the next stage of decomposition (stage IV, 553-573 K), the gas phase is composed of $\mathrm{Cu}-\mathrm{AMD}$, HAMD, $\mathrm{C}_{4} \mathrm{~F}_{9} \mathrm{COOH}$ [59], $\mathrm{CF}_{3} \mathrm{CFO}, \mathrm{C}_{2} \mathrm{~F}_{5} \mathrm{CN}, \mathrm{CO}_{2}$, and $\mathrm{CO}$. At higher temperatures (stage $V, 593-613 \mathrm{~K}$ ), the amount of gaseous products decreased, and $\mathrm{Cu}-\mathrm{AMD}$, $\mathrm{HAMD}$, carboxylic acid, and $\mathrm{CF}_{3} \mathrm{CFO}$ were observed. Finally, in the last stage of decomposition (stage VI, 633-753 K), the gas phase consists only of $\mathrm{CF}_{2}=\mathrm{CF}-\mathrm{CF}_{3}$ and $\mathrm{C}_{4} \mathrm{~F}_{9} \mathrm{COOH}$ (Figure $\mathrm{S} 7$ ).

Based on the VT IR spectra and the ions observed in the gas phase during the EI MS experiments (Section 3.4), the thermal decomposition mechanism of compounds (1)-(4) was proposed, as shown in Figure 7.

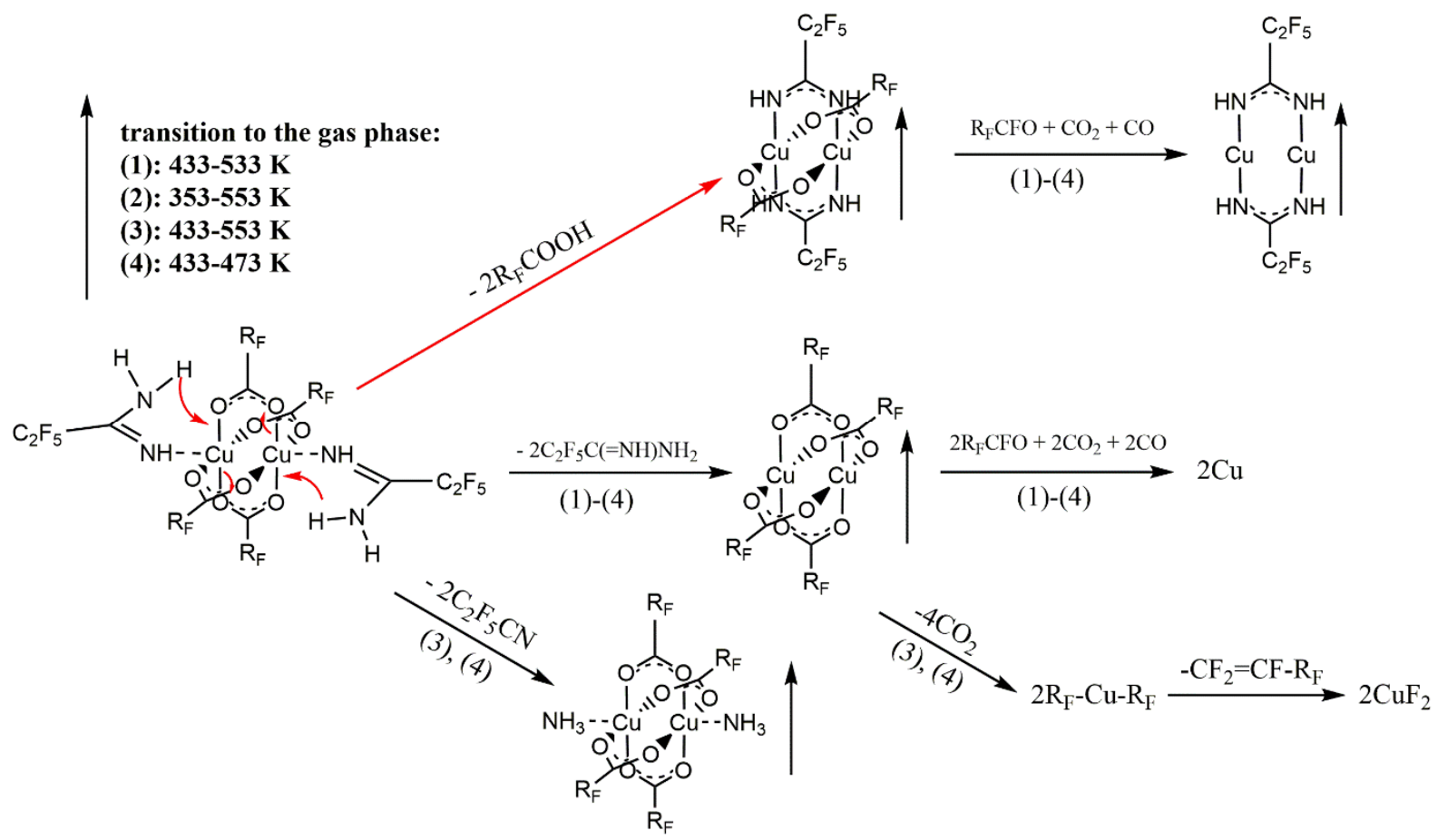

Figure 7. Proposed mechanism of $\left[\mathrm{Cu}_{2}(\mathrm{AMDH})_{2}\left(\mu-\mathrm{O}_{2} \mathrm{CR}_{\mathrm{F}}\right)_{4}\right]$ thermal decomposition based on VT IR and EI MS studies.

Based on the results described above, it can be concluded that complex (2) has the highest volatility. It was observed in the gas phase in the broadest temperature range. Moreover, the bands characteristic of this compound have a higher intensity than the bands assigned to degradation products in the temperature range of 433-533 K (Figure $8 \mathrm{~b}$ ). The inverse relationship was observed for compounds (1), (3), and (4) (Figure 8a,c,d). This means that complex (2) demonstrates the highest concentration in the gas phase. It is also worth adding that the concentration of other metal carriers is equally high. For this reason, 
this compound was selected as the best of the newly synthesised potential CVD precursors. Another compound ensuring a satisfactory amount of metal carriers in the gas phase was complex (3), which was also selected for testing in the CVD process.

a)

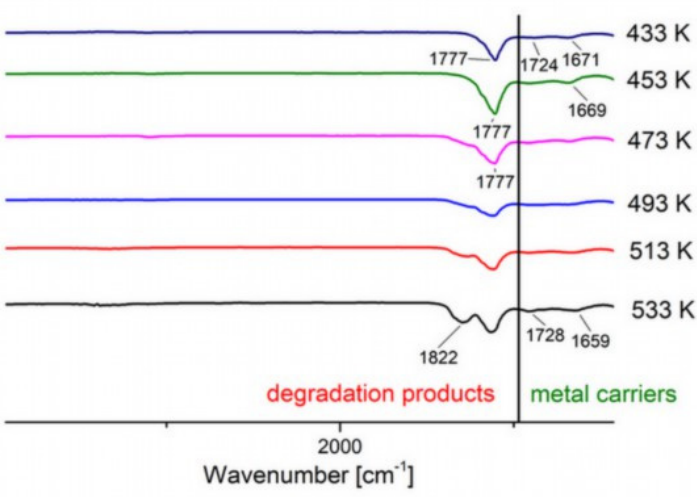

c)

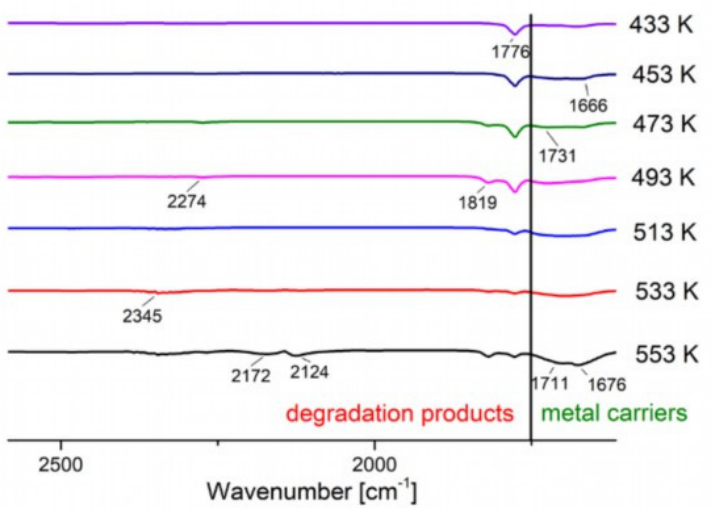

b)

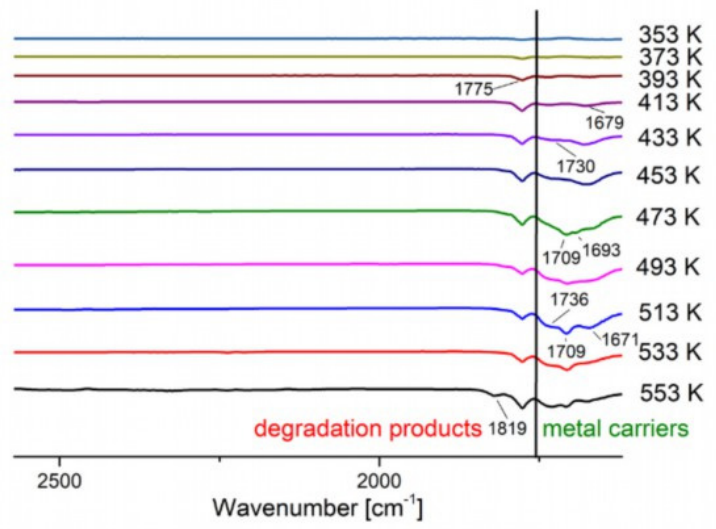

d)

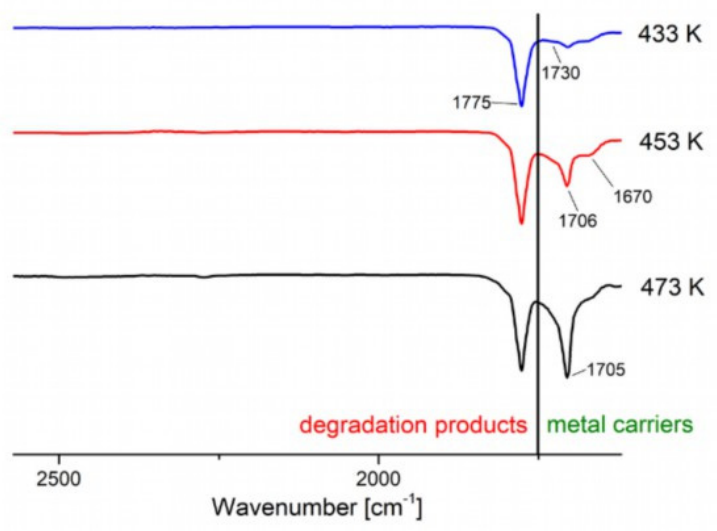

Figure 8. Enlargement of the area of occurrence of metal carriers (green) and degradation products' (red) characteristic bands: (a) $\left[\mathrm{Cu}_{2}(\mathrm{AMDH})_{2}\left(\mu-\mathrm{O}_{2} \mathrm{CCF}_{3}\right)_{4}\right](\mathbf{1}),(\mathrm{b})\left[\mathrm{Cu}_{2}(\mathrm{AMDH})_{2}\left(\mu-\mathrm{O}_{2} \mathrm{CC}_{2} \mathrm{~F}_{5}\right)_{4}\right]$ (2), (c) $\left[\mathrm{Cu}_{2}(\mathrm{AMDH})_{2}\left(\mu-\mathrm{O}_{2} \mathrm{CC}_{3} \mathrm{~F}_{7}\right)_{4}\right](3)$, (d) $\left[\mathrm{Cu}_{2}(\mathrm{AMDH})_{2}\left(\mu-\mathrm{O}_{2} \mathrm{CC}_{4} \mathrm{~F}_{9}\right)_{4}\right](4)$.

The obtained complexes (1)-(4) have higher volatility than analogues with tertbutylamine, because the complexes $\left[\mathrm{Cu}_{2}(\mathrm{AMDH})_{2}\left(\mu-\mathrm{O}_{2} \mathrm{CR}_{\mathrm{F}}\right)_{4}\right]$ go into the gas phase in the temperature range of $353-553 \mathrm{~K}$, while the $\left[\mathrm{Cu}_{2}\left(\mathrm{NH}_{2}{ }^{\mathrm{t}} \mathrm{Bu}\right)_{2}\left(\mu-\mathrm{O}_{2} \mathrm{CR}_{\mathrm{F}}\right)_{4}\right]$ compounds are a source of metal carriers over the temperature range of $373-553 \mathrm{~K}$ [42].

It is also worth noting that relatively small changes in the compound structure (the carbon chain length increased in the carboxylate) affect the mechanism of compound decomposition. One interesting observation is the lack of a simple correlation between the carbon chain length in the carboxylate and complex volatility. Both complex (1) and complex (4) have a low concentration in the gas phase.

Compared with the mass spectrometry results, no characteristic signals for carbodiimide or perfluorinated hydrocarbons (for compounds (1) and (2)) were detected in the VT IR spectra. It can be concluded that these products are formed only as a result of electron-induced decomposition rather than thermal decomposition. This observation confirms that VT IR spectra are an effective method for testing CVD precursors because the measurement conditions $\left(10^{-1} \mathrm{mbar}\right)$ are close to those in the used CVD reactor.

\subsection{Sublimation Experiments}

To further investigate the volatile species, sublimation experiments at $393 \mathrm{~K}$ and $1.3 \times 10^{-4}$ mbar were performed for compounds (1) and (2). Then, IR spectra were taken for the compounds deposited on the cooling finger. As can be seen for compound (2), the 
spectra before and after sublimation are similar (Figure 9 bottom). There are only slight differences in the positions and intensities of the bands assigned to the $\mathrm{N}-\mathrm{H}$ stretching and deformation vibration. Therefore, it can be concluded that compound (2) evaporates without decomposition. In the case of compound (1), the changes in the IR spectra before and after sublimation are much more noticeable (Figure 9 top). It is worth mentioning that there are bands in the spectrum of the sublimation product characteristic for both coordinated ligands $\left(3155 \mathrm{~cm}^{-1}, v_{\mathrm{N}-\mathrm{H}} ; 1724 \mathrm{~cm}^{-1}, v_{\mathrm{C}=\mathrm{N}} ; 1666 \mathrm{~cm}^{-1}, v_{\mathrm{C}=\mathrm{O}} ; 1543 \mathrm{~cm}^{-1}\right.$, $\left.\delta_{\mathrm{NH}}\right)$. This proves that compound (1) is a source of the metal carrier in the gas phase. It is likely that, during heating, a rearrangement in the structure of the compound occurs. The reason may be the breaking of hydrogen bonds between the molecules of the heated compound [60].

$\left[\mathrm{Cu}_{2}(\mathrm{AMDH})_{2}\left(\mu-\mathrm{O}_{2} \mathrm{CCF}_{3}\right)_{4}\right](1)$
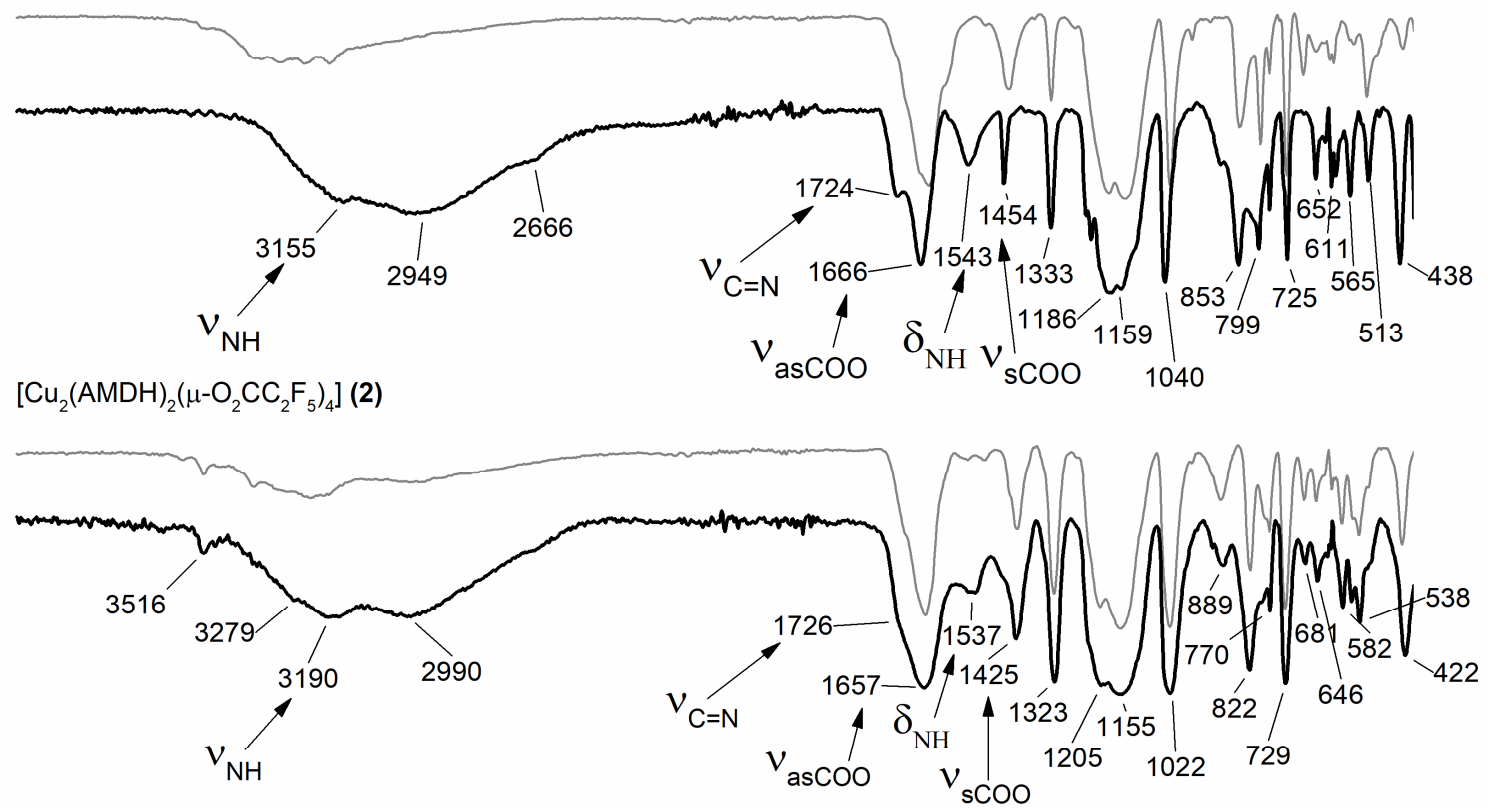

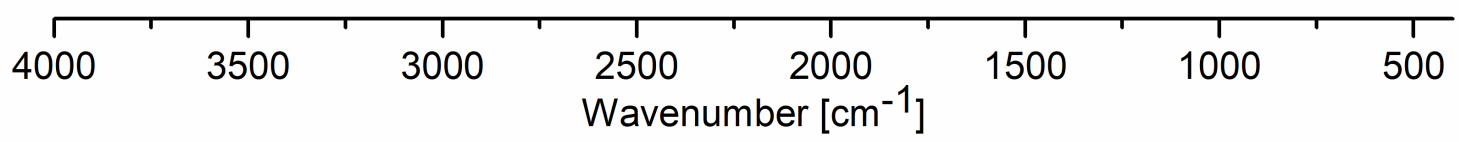

Figure 9. Infrared spectra for the compound $\left[\mathrm{Cu}_{2}(\mathrm{AMDH})_{2}\left(\mu-\mathrm{O}_{2} \mathrm{CCF}_{3}\right)_{4}\right](1)$ (top) and $\left[\mathrm{Cu}_{2}(\mathrm{AMDH})_{2}\left(\mu-\mathrm{O}_{2} \mathrm{CC}_{2} \mathrm{~F}_{5}\right)_{4}\right](2)$ (bottom) before sublimation (gray) and after sublimation (black).

\subsection{TEM and SEM Observations}

To initially assess the sensitivity of compound (2) to the high-energy electron beam, observations were made using a scanning electron microscope (SEM, $20 \mathrm{keV}$ ) and a transmission electron microscope (TEM, $200 \mathrm{keV}$ ). Complex (2) was selected for testing because it demonstrates the best volatility. For SEM analysis, the compound was prepared by depositing its layer on a silicon wafer using the earlier described sublimation method (Section 3.6). For TEM analysis, the compound was dissolved in ethanol, and the resulting solution was applied to a mesh and allowed to solvent evaporate.

EDX spectra were taken during the SEM analysis, each of them recorded for $30 \mathrm{~s}$. During the experiment, the scanning area was reduced, which increases the dose of electrons (Figure 10). With the increasing dose of electrons, the oxygen content decreases, the carbon content is slightly reduced, and the copper content increases. The contents of the other elements were almost the same. 


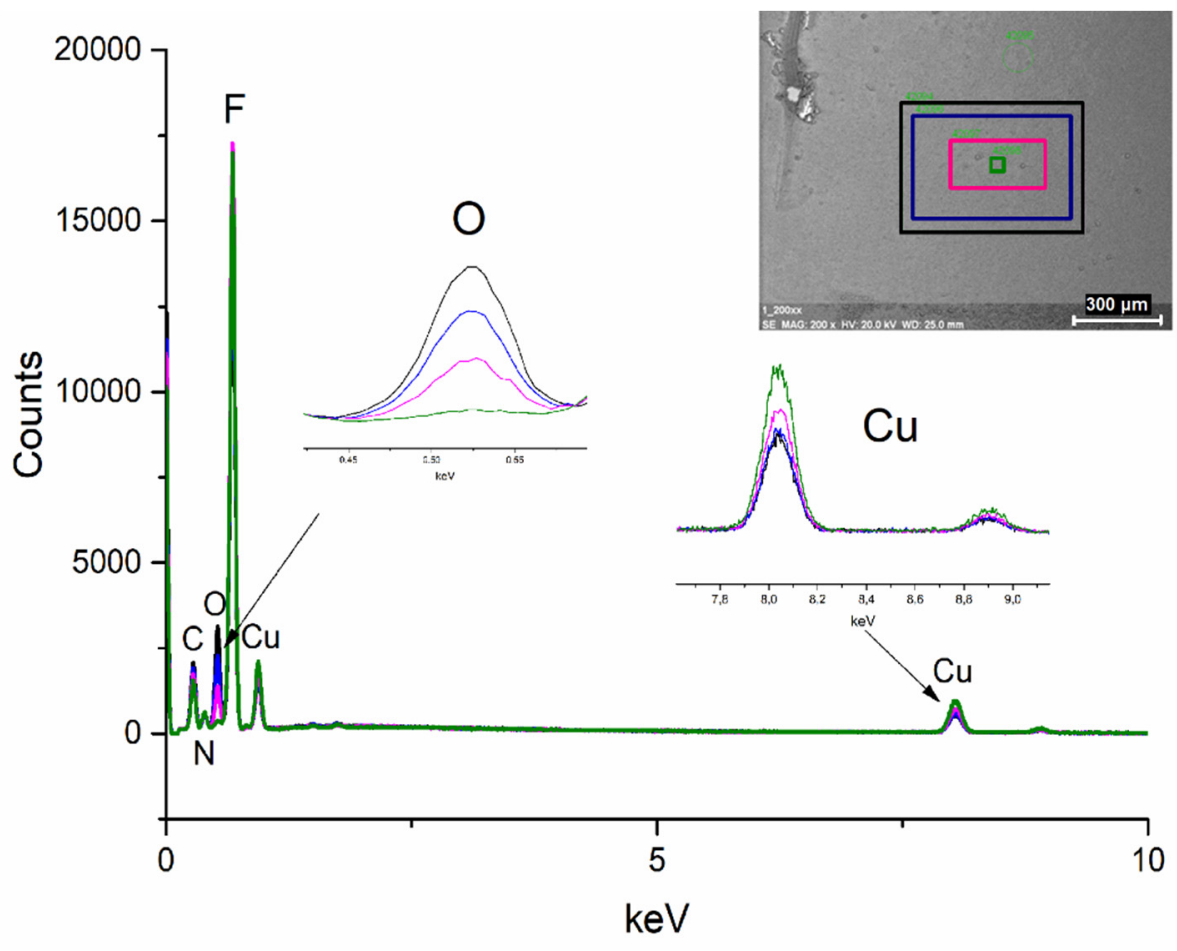

Figure 10. Examined scan areas' EDX spectra for $\left[\mathrm{Cu}_{2}(\mathrm{AMDH})_{2}\left(\mathrm{O}_{2} \mathrm{CC}_{2} \mathrm{~F}_{5}\right)_{4}\right](2)$ deposited on a silicon wafer.

Based on the obtained results and the mass spectra (Section 3.4), the following mechanism of the compound decomposition under SEM conditions was proposed. In the first stage, a proton transfer from the amidine molecule to the carboxylate probably took place, resulting in the formation of a coordinated deprotonated amidine and $\mathrm{C}_{2} \mathrm{~F}_{5} \mathrm{COOH}$ (Figure 11). Ions with deprotonated amidine were observed in EI MS spectra (Table 3). Acid was decomposed by electrons, forming $\mathrm{CO}_{2}$ and $\mathrm{C}_{2} \mathrm{~F}_{5} \mathrm{H}$. This is confirmed by the EI MS spectra of the complexes (Section 3.4) and $\mathrm{C}_{2} \mathrm{~F}_{5} \mathrm{COOH}$ [61], in which no molecular ion derived from the acid was observed. The unchanged amount of fluorine before compound interaction with electrons may indicate that $\mathrm{C}_{2} \mathrm{~F}_{5} \mathrm{H}$ has not been released from the layer as a gas. Stoffels et al. proved by electron attachment mass spectrometry experiment that, in radio frequency fluorocarbon plasmas of $\mathrm{CF}_{4}, \mathrm{C}_{2} \mathrm{~F}_{6}$, and $\mathrm{C}_{4} \mathrm{~F}_{8}$, polymerisation occurred readily, and molecules containing up to ten carbon atoms have been found [62]. Therefore, it is possible that, during the interaction of $\mathrm{C}_{2} \mathrm{~F}_{5} \mathrm{H}$ with the electron beam, polymerisation has occurred, and a carbon-fluorine matrix was formed.

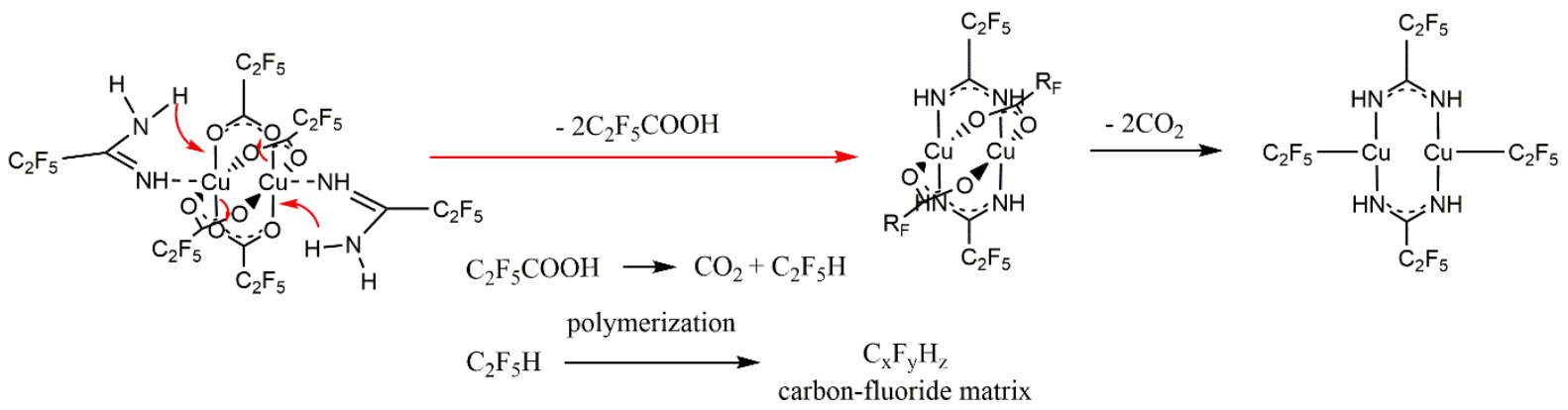

Figure 11. Proposed mechanism of $\left[\mathrm{Cu}_{2}(\mathrm{AMDH})_{2}\left(\mathrm{O}_{2} \mathrm{CC}_{2} \mathrm{~F}_{5}\right)_{4}\right](2)$ decomposition under the influence of an electron beam in the SEM microscope.

In the second stage of decomposition, decarboxylation occurred, and the perfluorinated groups were still bound to the central atom. Formation of $\left[\mathrm{Cu}\left(\mathrm{CF}_{3}\right)_{2}\right]^{-}$ion, with 
fluorocarbon group bonded to the copper atom, has been proved by Rijs et al. in their research on the mechanism of decomposition of $\left[\mathrm{Cu}_{2}\left(\mu-\mathrm{O}_{2} \mathrm{CCF}_{3}\right)_{4}\right]$ using mass spectrometry [63]. Moreover, in the electron collision experiments with $\left[\mathrm{Cu}_{2}\left(\mu-\mathrm{O}_{2} \mathrm{CC}_{2} \mathrm{~F}_{5}\right)_{4}\right]$, the $\left[\mathrm{Cu}\left(\mathrm{CF}_{3}\right)_{2}\right]^{-}$ion was formed [64].

It is seen that, during the interaction of the electron beam with a solid-phase compound, the amount of energy under SEM conditions is insufficient to remove the coordinated ligands effectively. The obtained results showed that the $\mathrm{Cu}-\mathrm{O}$ bond is the weakest in the complex. The proposed mechanism of compound decomposition under the influence of the SEM electron beam is presented in Figure 11. It still seems necessary to conduct FEBID experiments because, in this method, the precursor is deposited from the gas phase and, as evidenced by the EI MS spectrum (Section 3.4), in which the precursor is in gaseous form and interact with low-energy electrons, it is possible to decompose it into copper(I) fluoride.

During TEM imaging, structural changes of the sample were visible from the beginning of the measurement. After a few seconds, only the image of the sample was stabilised, and crystallites were observed (Figure 12). The obtained diffraction confirmed the crystallinity of the formed substance with diffraction rings matching the cubic $\mathrm{CuF}_{2}$.

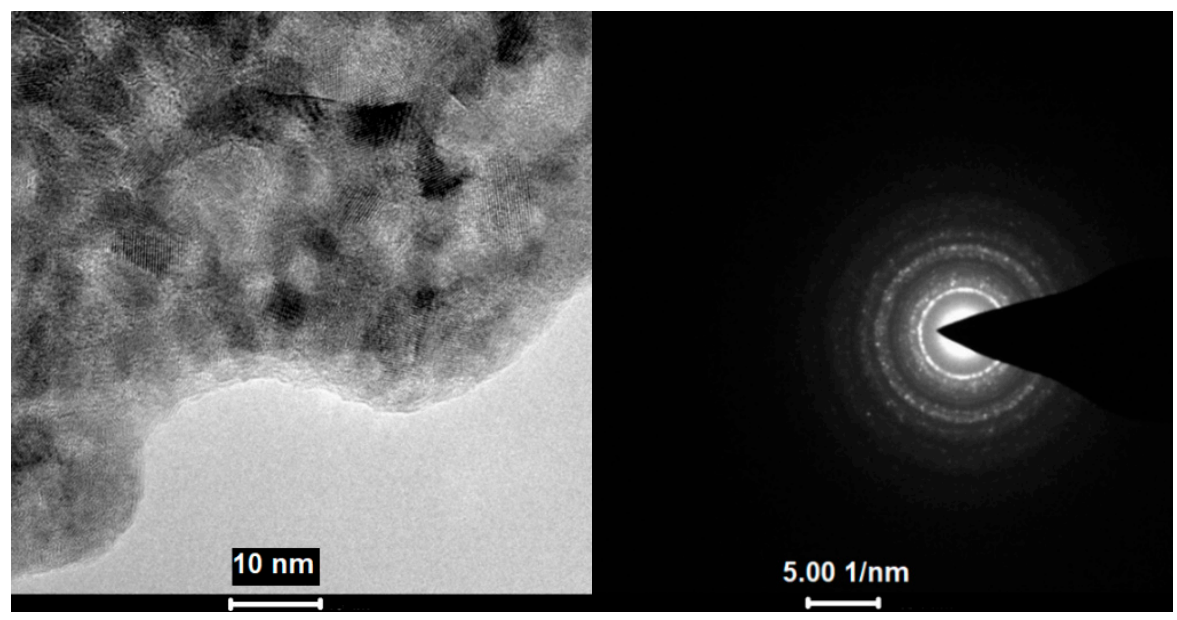

Figure 12. Image of the sample after a few seconds of $\left[\mathrm{Cu}_{2}(\mathrm{AMDH})_{2}\left(\mathrm{O}_{2} \mathrm{CC}_{2} \mathrm{~F}_{5}\right)_{4}\right](2)$ interaction with electrons and diffraction pattern, which confirms the crystallinity of the deposit.

The EDX spectra of the TEM obtained material showed the following atomic contents of the elements: 11.6 at.\% Cu, 41.2 at. $\%$ F, and 47.2 at.\% C. Such values suggest that, apart from copper(II) fluoride formation, after the compound (2) interaction with the high-energy electron beam, a matrix consisting of fluorine and carbon is formed. However, it should be taken into account that the TEM grid was covered with carbon, which affects the semiquantitative measurement. It is worth noting that the resulting material does not contain oxygen and nitrogen, which were in the pristine compound (2). This may indicate the breaking of $\mathrm{Cu}-\mathrm{N}$ and $\mathrm{Cu}-\mathrm{O}$ bonds under the conditions of TEM observation. The proposed mechanism of compound decomposition under the influence of the TEM electron beam is presented in Figure 13.

The microscopic observations showed that compound (2) is sensitive to the highenergy electron beam. It is visible that the decomposition of the compound strongly depends on the beam power and electron dose. When high electron energy (TEM) is used, $\mathrm{CuF}_{2}$ is the final decomposition product, but in $\mathrm{SEM}, \mathrm{CO}_{2}$ detachment and organometallic species formation were suggested, while electrons have low energy (EI MS, Section 3.4), and $\mathrm{Cu}_{2} \mathrm{~F}_{2}$ is formed. 


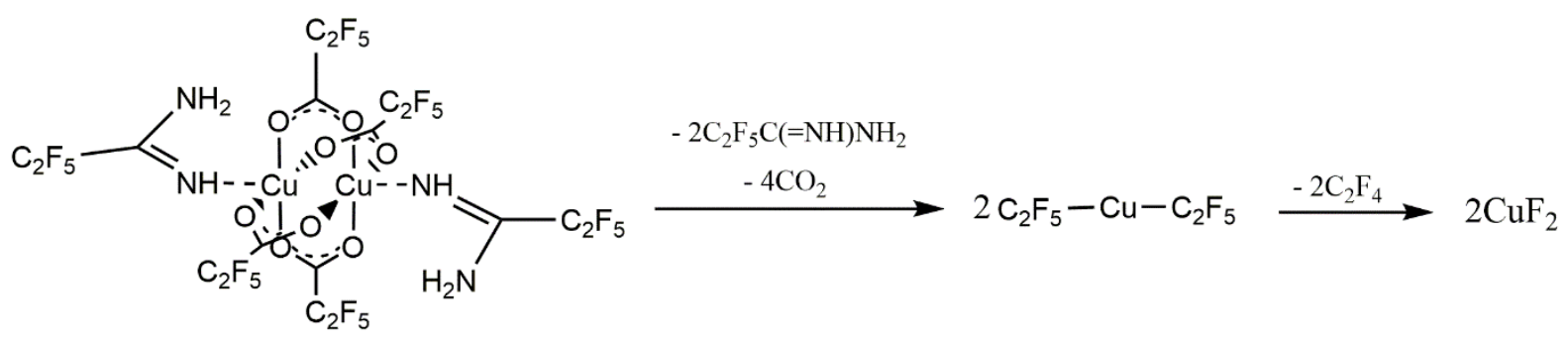

Figure 13. Proposed mechanism of $\left[\mathrm{Cu}_{2}(\mathrm{AMDH})_{2}\left(\mathrm{O}_{2} \mathrm{CC}_{2} \mathrm{~F}_{5}\right)_{4}\right](2)$ decomposition under the influence of an electron beam under the TEM analysis conditions.

\subsection{CVD Preliminary Experiments}

Based on the volatility studies (TA, EI MS, VT IR-Sections 3.3-3.5), complexes (2) and (3) were selected for the hot-wall CVD experiments (Table 4). In the case of complex (2), the evaporation temperature of $393 \mathrm{~K}$ was sufficient to deposit the layer, while for precursor (3), it was necessary to increase the temperature to $453 \mathrm{~K}$. This is consistent with the results of the VT IR analysis (Section 3.5), because for complex (2), the bands characteristic for the copper carriers appeared at lower temperatures (353 K) than for the complex (3) (433 K), and additionally they had higher intensities, which indicates a higher concentration of these metal carriers in the gas phase. The process was carried out using decomposition temperatures from $573 \mathrm{~K}$ to $633 \mathrm{~K}$. The best results were obtained using $633 \mathrm{~K}$ as the deposition temperature $\mathrm{T}_{\mathrm{D}}$.

Table 4. Summary of chemical vapour deposition (CVD) conditions for the compounds (2) and (3).

\begin{tabular}{cc}
\hline Precursor & \\
\hline Precursor mass $(\mathrm{m})[\mathrm{mg}]$ & 100 \\
Vaporization temperature $\left(\mathrm{T}_{\mathrm{V}}\right)[\mathrm{K}]$ & $393(\mathbf{2}), 453(\mathbf{2}),(\mathbf{3})$ \\
Deposition temperature $\left(\mathrm{T}_{\mathrm{D}}\right)[\mathrm{K}]$ & $573-633$ \\
Carrier gas & $\mathbf{A r}$ \\
Substrates & $\mathrm{Si}(111)$ \\
Deposition time $(\mathrm{t})[\mathrm{min}]$ & 60 \\
\hline
\end{tabular}

The deposited layer was smooth (Figures $14 \mathrm{~b}$ and $15 \mathrm{~b}$ ), and no impurity signals $(\mathrm{C}, \mathrm{N}, \mathrm{O})$ were observed in the EDX spectrum (Figure 16a, red line).

In the case of compound (2), nanometric layers with a thickness of 69-360 nm were produced (Figure 14). It is seen that the higher evaporation temperature of the precursor results in a greater layer thickness (Figure 14a). This is consistent with the spectra of infrared spectroscopy because, at $393 \mathrm{~K}$ (Figure 8b), the concentration of the metal carriers in the gas phase was much lower than at $453 \mathrm{~K}$ (Figure $8 \mathrm{~b}$ ). Using the higher vaporization temperature $\left(T_{V}=453 \mathrm{~K}\right)$ and lower deposition temperature $\left(T_{D}=593 \mathrm{~K}\right)$ (Figure $\left.14 \mathrm{a}\right)$, the grains (51-254 nm, Figure 15a) were more dispersed than at $T_{V}=393 \mathrm{~K}$ and $T_{D}=633 \mathrm{~K}$ (Figure $14 b-d$ ). The calculated roughness parameter $R_{a}$ for the layer shown in Figure $14 a$ was $51.0 \mathrm{~nm}$, while for the films shown in Figure $14 \mathrm{~b}-\mathrm{d}$, it was $11.1 \mathrm{~nm}, 11.1 \mathrm{~nm}$, and $9.4 \mathrm{~nm}$, respectively. This confirms that the layers deposited at lower vaporization and higher deposition temperature were smoother. The grain size for the films deposited at the higher temperatures was in the range of 36-201 nm (Figure 15c,d). Moreover, using a shorter transport way of the metal carriers, densely packed single grains with a size of $138-445 \mathrm{~nm}$ were obtained (Figure 15b).

In the layer with a thickness of $69 \mathrm{~nm}$ deposited with complex (3), single, densely packed, round shape grains were also formed (Figure 17a). The continuity of the layer is also confirmed by the low value of the roughness parameter $\left(R_{a}=9.9 \mathrm{~nm}\right)$. It is worth noting that using a higher evaporation temperature $\mathrm{T}_{\mathrm{V}}$ from $551 \mathrm{~K}(3)$ to $586 \mathrm{~K}$ for complex (3) leads to obtaining layers of similar thickness than when using a lower temperature for precursor (2). This also confirms the lower volatility of compound (3). 
It is worth adding that both the precursor evaporation and decomposition temperatures were lower for the complex with perfluorinated amidine than for the previously used complex with ${ }^{\mathrm{t}} \mathrm{BuNH}_{2}\left[\mathrm{Cu}_{2}\left({ }^{\mathrm{t}} \mathrm{BuNH}_{2}\right)_{2}\left(\mu-\mathrm{O}_{2} \mathrm{CR}_{\mathrm{f}}\right)_{4}\right]$, which was $393 \mathrm{~K}, 453 \mathrm{~K}$ (amidine); 435-473 $\mathrm{K}\left({ }^{\mathrm{t}} \mathrm{BuNH}_{2}\right)$ and $573-633 \mathrm{~K}$ (amidine); 623-733 $\mathrm{K}\left({ }^{\mathrm{t}} \mathrm{BuNH}_{2}\right)$, respectively [42]. This shows that the introduction of a secondary perfluorinated ligand in the axial position increases the volatility of the compounds.

The EDX (SEM analysis) and XRD spectra of the layers showed that they contain metallic copper (Figure 16a,b and Figure 17b,c). The formation of metallic copper during the CVD process was also confirmed by the diffraction patterns and EDX spectra obtained by TEM analysis (Figures $16 \mathrm{c}$ and $17 \mathrm{~d}, \mathrm{e}$ ). The great advantage of compound (2) is that it was possible to obtain pure copper films from the air-stable copper(II) complex in an argon atmosphere without using an additional reducing agent. However, in the case of complex (3), apart from metallic copper, copper(I) oxide and a small amount of carbon (2.9 at.\%) were also detected. In contrast, the layers deposited with the use of $\left[\mathrm{Cu}_{2}\left(\mathrm{NH}_{2}{ }^{\mathrm{t}} \mathrm{Bu}\right)_{2}(\mu-\right.$ $\left.\mathrm{O}_{2} \mathrm{CR}_{\mathrm{F}}\right)_{4}$ ] precursors contained metallic copper and a low content of fluorine (1.5 at.\%) [42]. Interestingly, despite the high content of fluorine in compounds (2) and (3), it is not present in the obtained deposits.
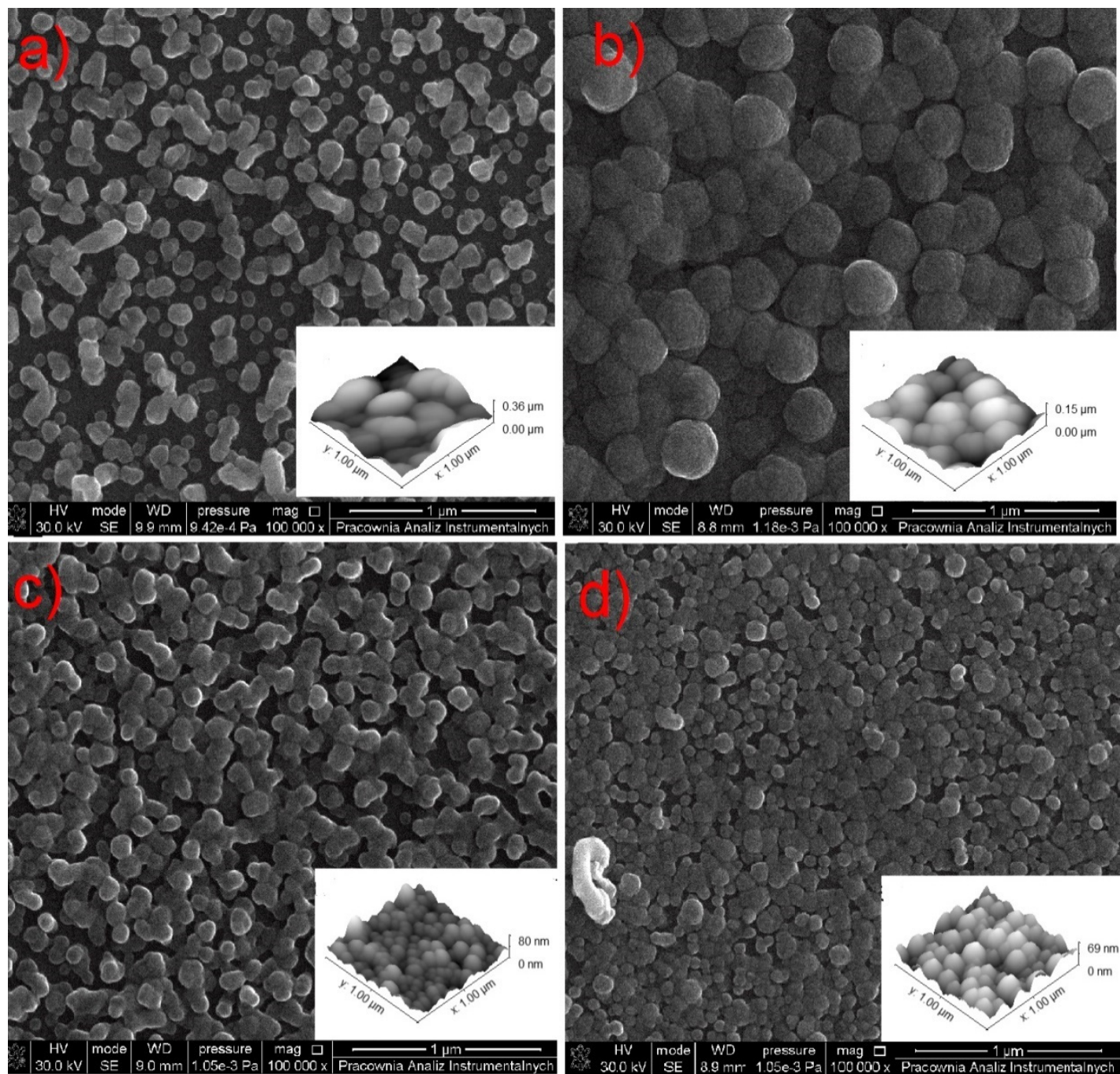

Figure 14. SEM and AFM results of preliminary chemical vapour deposition (CVD) experiment using $\left[\mathbf{C u}_{2}(\mathbf{A M D H})_{2}\left(\mathbf{O}_{2} \mathbf{C C}_{2} \mathrm{~F}_{5}\right)_{4}\right]$ (2): (a) $\mathrm{T}_{\mathrm{V}}=453 \mathrm{~K}, \mathrm{~T}_{\mathrm{D}}=593 \mathrm{~K} ;(\mathbf{b}-\mathbf{d}) \mathrm{T}_{\mathrm{V}}=393 \mathrm{~K}, \mathrm{~T}_{\mathrm{D}}=633 \mathrm{~K}$, in the case of (b)), the transport way of vapours was shorter. 

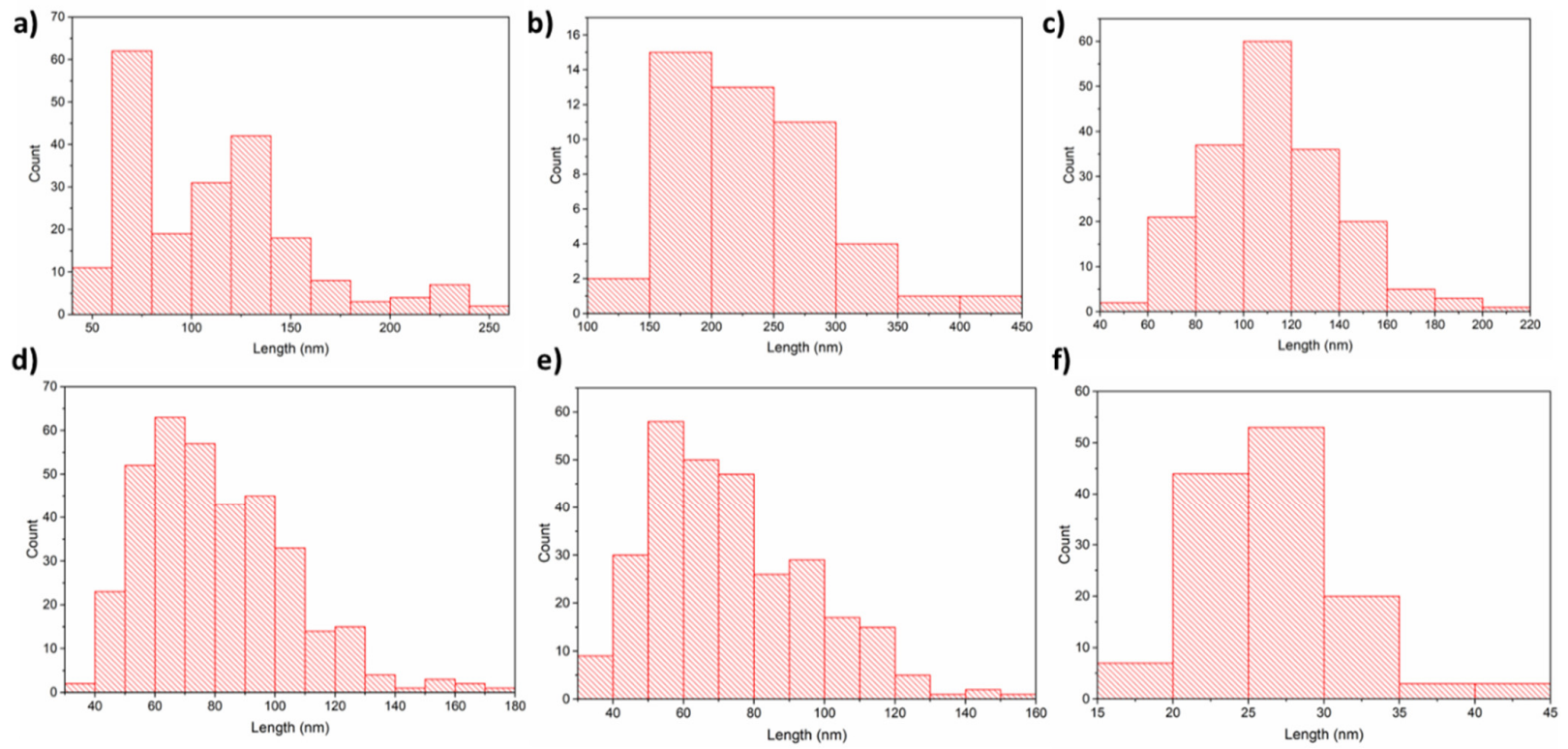

Figure 15. Histograms of a grain-size distribution: (a) $\left.\left[\mathbf{C u}_{\mathbf{2}}(\mathbf{A M D H})_{\mathbf{2}}\left(\mathbf{O}_{\mathbf{2}} \mathbf{C C}_{\mathbf{2}} \mathbf{F}_{\mathbf{5}}\right)_{\mathbf{4}}\right] \mathbf{( 2 )}\right), \mathrm{T}_{\mathrm{V}}=453 \mathrm{~K}, \mathrm{~T}_{\mathrm{D}}=593 \mathrm{~K}$; $(\mathrm{b}-\mathrm{d})\left[\mathrm{Cu}_{2}(\mathrm{AMDH})_{2}\left(\mathrm{O}_{2} \mathrm{CC}_{2} \mathrm{~F}_{5}\right)_{4}\right](\mathbf{2}), \mathrm{T}_{\mathrm{V}}=393 \mathrm{~K}, \mathrm{~T}_{\mathrm{D}}=633 \mathrm{~K}$, in the case of $(\mathrm{b})$, the transport way of vapours was shorter; (e) $\left[\mathrm{Cu}_{2}(\mathrm{AMDH})_{2}\left(\mu-\mathrm{O}_{2} \mathrm{CC}_{3} \mathrm{~F}_{7}\right)_{4}\right](\mathbf{3}), \mathrm{T}_{\mathrm{V}}=453 \mathrm{~K}, \mathrm{~T}_{\mathrm{D}}=633 \mathrm{~K} ;(\mathbf{f})\left[\mathrm{Cu}_{2}(\mathrm{AMDH})_{2}\left(\mu-\mathrm{O}_{2} \mathbf{C C}_{3} \mathrm{~F}_{7}\right)_{4}\right](3) \mathrm{T}_{\mathrm{V}}=393 \mathrm{~K}, \mathrm{~T}_{\mathrm{D}}=573 \mathrm{~K}$.
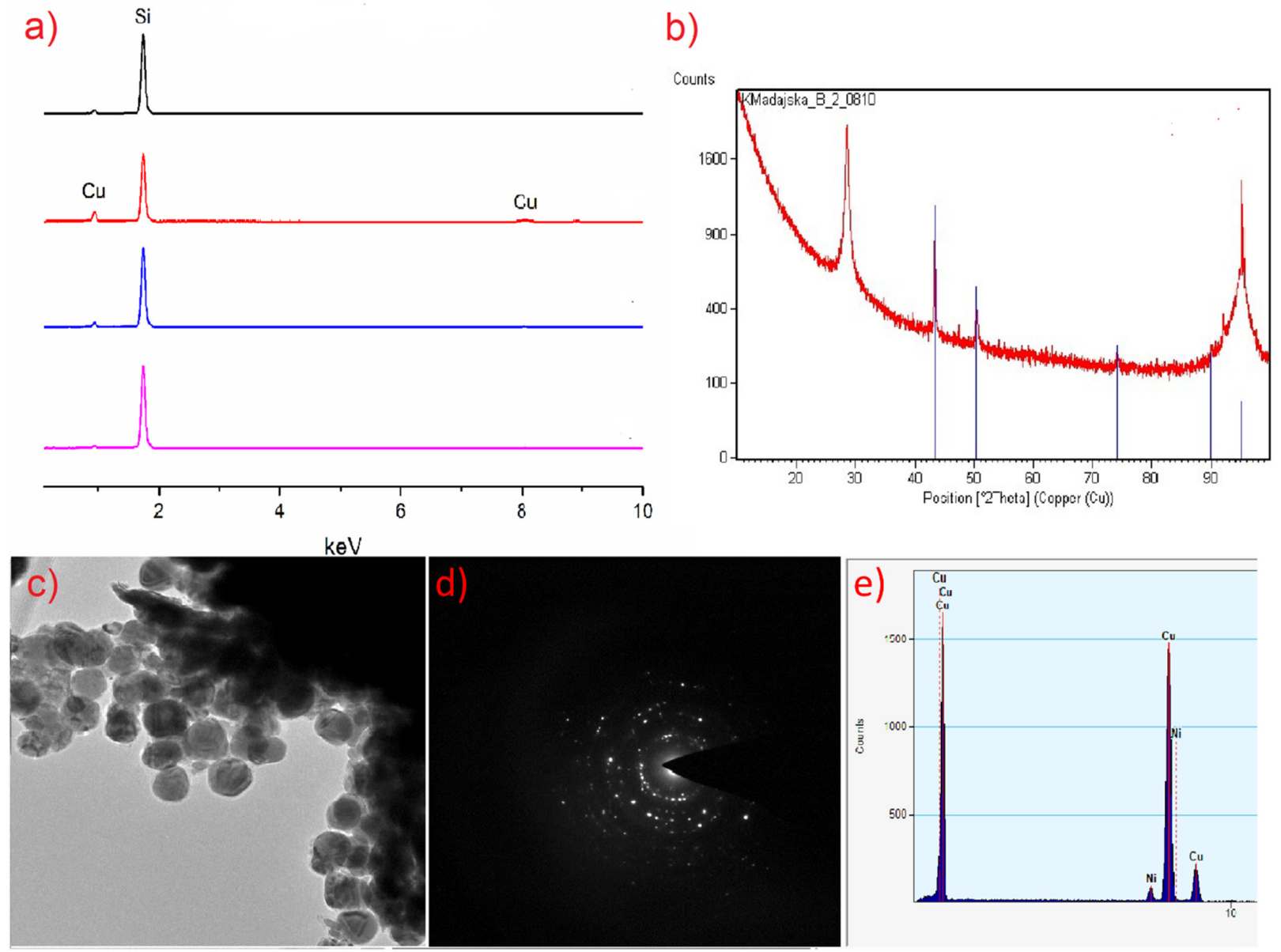

Figure 16. Composition analysis of the obtained layers using precursor (2) $\left[\mathrm{Cu}_{\mathbf{2}}(\mathrm{AMDH})_{\mathbf{2}}\left(\mu-\mathrm{O}_{\mathbf{2}} \mathrm{CC}_{\mathbf{2}} \mathrm{F}_{5}\right)_{\mathbf{4}}\right]$ : (a) EDX spectra: black line: $\mathrm{T}_{\mathrm{V}}=453 \mathrm{~K}, \mathrm{~T}_{\mathrm{D}}=593 \mathrm{~K}$; red, blue and pink line: $\mathrm{T}_{\mathrm{V}}=393 \mathrm{~K}, \mathrm{~T}_{\mathrm{D}}=633 \mathrm{~K}$, in the case of the red line, the transport way of vapours was shorter; (b) XRD analysis; (c) TEM image; (d) diffraction pattern; (e) EDX spectra from TEM. 

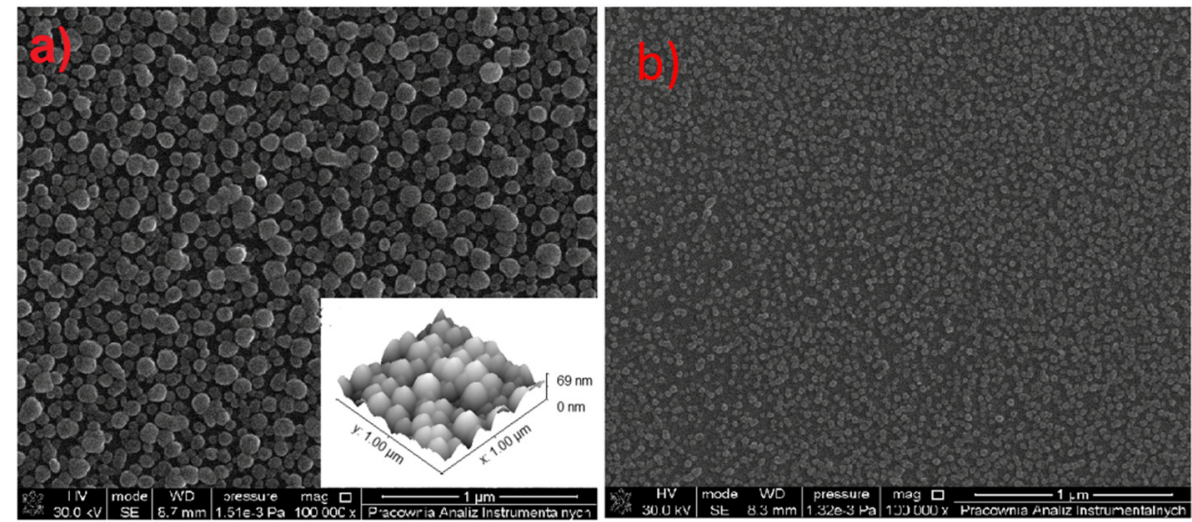

d)

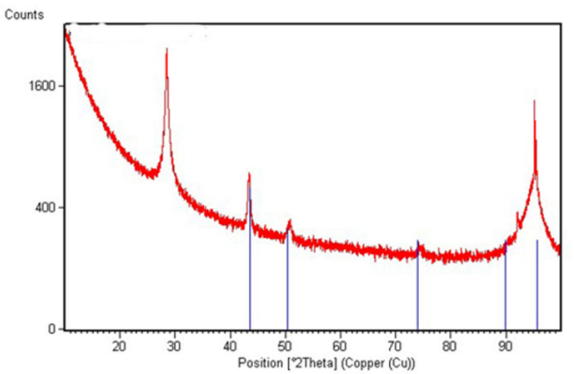

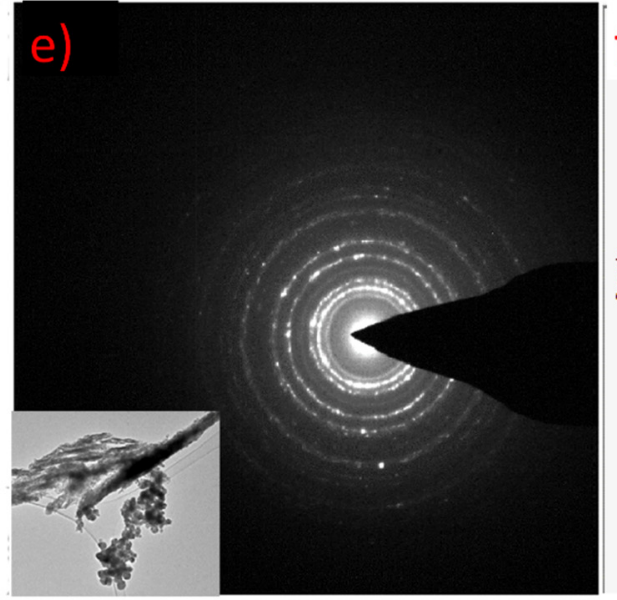

c)

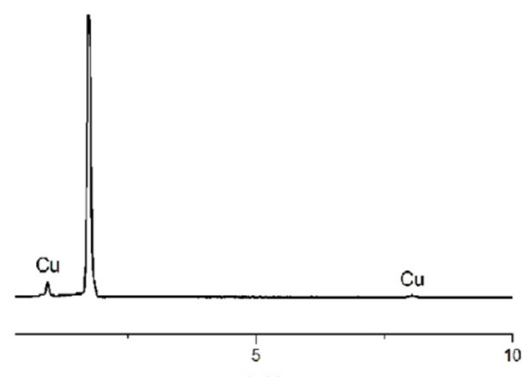

$\mathrm{keV}$

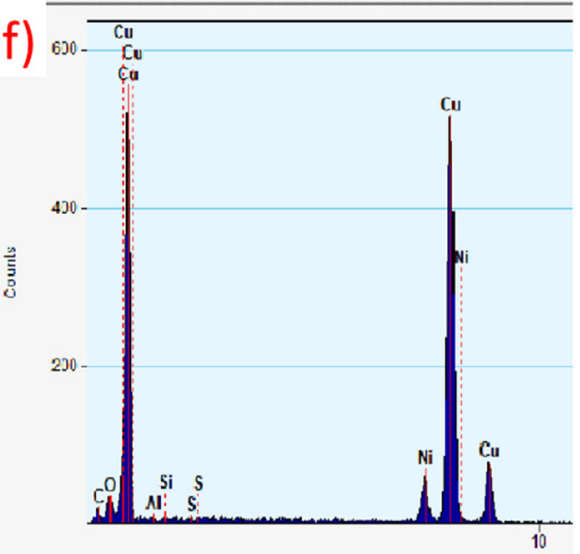

Figure 17. (a) SEM and AFM results of preliminary CVD experiments for the $\left[\mathrm{Cu}_{2}(\mathrm{AMDH})_{2}\left(\mu-\mathrm{O}_{2} \mathrm{CC}_{3} \mathrm{~F}_{7}\right)_{4}\right]$ precursor $(3)$ $\mathrm{T}_{\mathrm{V}}=453 \mathrm{~K}, \mathrm{~T}_{\mathrm{D}}=633 \mathrm{~K}$; (b) SEM results, $\left[\mathrm{Cu}_{2}(\mathrm{AMDH})_{2}\left(\mu-\mathrm{O}_{2} \mathbf{C C}_{3} \mathrm{~F}_{7}\right)_{4}\right](3), \mathrm{T}_{\mathrm{V}}=393 \mathrm{~K}, \mathrm{~T}_{\mathrm{D}}=573 \mathrm{~K}$; (c) EDX spectra from SEM; (d) XRD spectra; (e) TEM image and diffraction pattern; (f) EDX spectra from TEM.

\section{Conclusions}

Copper(II) carboxylate compounds with perfluorinated amidine of the general formula $\left[\mathrm{Cu}_{2}(\mathrm{AMDH})_{2}\left(\mu-\mathrm{O}_{2} \mathrm{CR}_{\mathrm{F}}\right)_{4}\right]$, where $\mathrm{R}_{\mathrm{F}}=\mathrm{CF}_{3}, \mathrm{C}_{2} \mathrm{~F}_{5}, \mathrm{C}_{3} \mathrm{~F}_{7}, \mathrm{C}_{4} \mathrm{~F}_{9}$, were obtained by the reaction of copper(II) perfluorinated carboxylates with perfluorinated amidine. The IR spectra analysis suggested the bridging coordination mode of carboxylates. $=\mathrm{NH}$-bonding of amidine was proposed from infrared spectra analysis and confirmed by DFT calculations. The structure of the obtained compounds was also confirmed by the results of the EI MS analysis. The following pseudomolecular ions $\left[\mathrm{Cu}_{2}(\mathrm{AMDH})_{2}\left(\mu-\mathrm{O}_{2} \mathrm{CR}_{\mathrm{F}}\right)_{3}\right]^{+}$proved the dimeric structure of the studied complexes with bridging carboxylates forming the "paddlewheel" structure and axially N-coordinated amidines. The results of mass spectrometry (MS-EI) and variable temperature infrared spectroscopy demonstrated that the synthesised compounds are a source of copper carriers in the gas phase. Studies have shown that the decomposition process of the compounds is complicated. However, two main mechanisms can be distinguished: amidine deprotonation and formation of volatile copper amidinates and a carboxylic acid, and amidine detachment followed by decarboxylation of copper carboxylate. Moreover, the thermal analysis showed that copper transfer to the gaseous phase occurred even at atmospheric pressure.

The preliminary CVD experiments confirmed that compounds (2) and (3) are the source of metal carriers in the gas phase. Complex (2) was also shown to be the most volatile. Copper films were successfully deposited using precursor $\left[\mathrm{Cu}_{2}(\mathbf{A M D H})_{\mathbf{2}}(\mu-\right.$ $\left.\left.\mathrm{O}_{2} \mathrm{CC}_{2} \mathrm{~F}_{5}\right)_{4}\right]$ (2) by the CVD method in the Ar atmosphere. The great advantage of the $\left[\mathrm{Cu}_{2}(\mathrm{AMDH})_{2}\left(\mu-\mathrm{O}_{2} \mathrm{CC}_{2} \mathrm{~F}_{5}\right)_{4}\right](2)$ is that a metallic film can be obtained from the air-stable copper(II) compound without the need to use any additional reducing agent such as $\mathrm{H}_{2}$. The best results (smooth and pure structures) were achieved when the temperature of the 
precursor evaporation was $393 \mathrm{~K}$, while the decomposition temperature was $633 \mathrm{~K}$. Thanks to our research, we have obtained a promising compound that can be used as a precursor in CVD methods. Moreover, based on the study of the complexes' interactions with high-energy electrons, it can be concluded that the energy and dose influence the deposit composition and compound $\left[\mathrm{Cu}_{2}(\mathrm{AMDH})_{2}\left(\mu-\mathrm{O}_{2} \mathrm{CC}_{2} \mathbf{F}_{5}\right)_{4}\right](2)$ may also be a precursor in the FEBID method for the preparation of nanostructures composed of copper(II) fluoride.

Supplementary Materials: The following are available online at https: / www.mdpi.com/article / $10.3390 / \mathrm{ma14123145/s1}$, Figure S1. Infrared spectra for the complex $\left[\mathrm{Cu}_{2}(\mathrm{AMDH})_{2}\left(\mu-\mathrm{O}_{2} \mathrm{CF}_{3}\right)_{4}\right]$ (1); Figure S2. Infrared spectra for the complex $\left[\mathrm{Cu}_{2}(\mathrm{AMDH})_{2}\left(\mu-\mathrm{O}_{2} \mathrm{C}_{2} \mathrm{~F}_{5}\right)_{4}\right](2)$; Figure S3. Infrared spectra for the complex $\left[\mathrm{Cu}_{2}(\mathrm{AMDH})_{2}\left(\mu-\mathrm{O}_{2} \mathrm{C}_{3} \mathrm{~F}_{7}\right)_{4}\right]$ (3); Figure S4. Infrared spectra for the complex $\left[\mathrm{Cu}_{2}(\mathrm{AMDH})_{2}\left(\mu-\mathrm{O}_{2} \mathrm{C}_{4} \mathrm{~F}_{9}\right)_{4}\right](4)$; Figure S5. VT IR spectra of $\left[\mathrm{Cu}_{2}(\mathrm{AMDH})_{2}\left(\mu-\mathrm{O}_{2} \mathrm{CCF}_{3}\right)_{4}\right](1)$ in the temperature range $333-753 \mathrm{~K}$; Figure 66 . VT IR spectra of $\left[\mathrm{Cu}_{2}(\mathrm{AMDH})_{2}\left(\mu-\mathrm{O}_{2} \mathrm{CC}_{3} \mathrm{~F}_{7}\right)_{4}\right](3)$ in the temperature range $333-613 \mathrm{~K}$; Figure S7. VT IR spectra of $\left[\mathrm{Cu}_{2}(\mathrm{AMDH})_{2}\left(\mu-\mathrm{O}_{2} \mathrm{CC}_{4} \mathrm{~F}_{9}\right)_{4}\right](4)$ in the temperature range $333-633 \mathrm{~K}$; Figure S8. IR spectrum in the gas phase at $353 \mathrm{~K}$ for the complex $\left[\mathrm{Cu}_{2}(\mathrm{AMDH})_{2}\left(\mu-\mathrm{O}_{2} \mathrm{CC}_{2} \mathrm{~F}_{5}\right)_{4}\right](2)$; Table S1. EI MS results for the complex $\left[\mathrm{Cu}_{2}(\mathrm{AMDH})_{2}\left(\mu-\mathrm{O}_{2} \mathrm{CF}_{3}\right)_{4}\right]$ (1); Table S2. EI MS results for the complex $\left[\mathrm{Cu}_{2}(\mathrm{AMDH})_{2}\left(\mu-\mathrm{O}_{2} \mathrm{C}_{3} \mathrm{~F}_{7}\right)_{4}\right]$ (3); Table S3. EI MS results for the complex $\left[\mathrm{Cu}_{2}(\mathrm{AMDH})_{2}\left(\mu-\mathrm{O}_{2} \mathrm{C}_{4} \mathrm{~F}_{9}\right)_{4}\right](4)$.

Author Contributions: Conceptualisation, K.M. and I.B.S.; investigation, K.M.; writing-original draft preparation, K.M.; writing—review and editing, I.B.S.; visualisation, K.M.; supervision, I.B.S.; funding acquisition, K.M. and I.B.S. All authors have read and agreed to the published version of the manuscript.

Funding: The financing of this work was by Nicolaus Copernicus University in Torun (PDB no.103).

Institutional Review Board Statement: Not applicable.

Informed Consent Statement: Not applicable.

Data Availability Statement: The data presented in this study are available on request from the corresponding author.

Acknowledgments: This research was supported in part by PL-Grid Infrastructure.

Conflicts of Interest: The authors declare no conflict of interest.

\section{References}

1. Padnya, P.; Shibaeva, K.; Arsenyev, M.; Baryshnikova, S.; Terenteva, O.; Shiabiev, I.; Khannanov, A.; Boldyrev, A.; Gerasimov, A.; Grishaev, D.; et al. Catechol-Containing Schiff Bases on Thiacalixarene: Synthesis, Copper (II) Recognition, and Formation of Organic-Inorganic Copper-Based Materials. Molecules 2021, 26, 2334. [CrossRef] [PubMed]

2. Li, X.; Zhong, X.; Hu, Y.; Li, B.; Sheng, Y.; Zhang, Y.; Weng, C.; Feng, M.; Han, H.; Wang, J. Organic-Inorganic Copper(II)-Based Material: A Low-Toxic, Highly Stable Light Absorber for Photovoltaic Application. J. Phys. Chem. Lett. 2017, 8, 1804-1809. [CrossRef]

3. Wang, L.; Sun, H.; Sun, C.; Xu, D.; Tao, J.; Wei, T.; Zhang, Z.; Zhang, Y.; Wang, Z.; Bi, W. Lead-free, stable orange-red-emitting hybrid copper based organic-inorganic compounds. Dalton Trans. 2021, 50, 2766-2773. [CrossRef]

4. Doniz Kettenmann, S.; Nossol, Y.; Louka, F.R.; Legrande, J.R.; Marine, E.; Fischer, R.C.; Mautner, F.A.; Hergl, V.; Kulak, N.; Massoud, S.S. Copper(II) Complexes with Tetradentate Piperazine-Based Ligands: DNA Cleavage and Cytotoxicity. Inorganics 2021, 9, 12. [CrossRef]

5. Hussain, A.; AlAjmi, M.F.; Rehman, M.T.; Amir, S.; Husain, F.M.; Alsalme, A.; Siddiqui, M.A.; AlKhedhairy, A.A.; Khan, R.A. Copper(II) complexes as potential anticancer and Nonsteroidal anti-inflammatory agents: In vitro and in vivo studies. Sci. Rep. 2019, 9, 1-17. [CrossRef]

6. Cao, M.G.; Wang, J.J.; Wang, Y.; Wang, X.F.; Li, J.X.; Chen, J.X.; Hu, B.Q.; Hu, D.D. Two cobalt(II) and copper(II) complexes with 2,4,5-tri(4-pyridyl)-imidazole and 5-hydroxyisophthalic acid as turn-on luminescence sensors for Mg2+, Ca2+ and SCN-ions. Z. Anorg. Allg. Chem. 2021, 647, 714-721. [CrossRef]

7. Kanso, H.; Ben Jrad, A.; Inguimbert, N.; Rammal, W.; Philouze, C.; Thomas, F.; Noguer, T.; Calas-Blanchard, C. Synthesis and Characterization of Bis-1,2,3-Triazole Ligand and its Corresponding Copper Complex for the Development of Electrochemical Affinity Biosensors. Chem. A Eur. J. 2021, 27, 1-10. [CrossRef]

8. Guo, R.-F.; Yan, H.-T.; Liu, R.-X.; Li, H.-C.; Liu, Y.-C.; Chen, Z.-F.; Liang, H. Structural characterization and pharmacological assessment: In vitro/in vivo of a new copper(ii)-based derivative of enrofloxacin. Metallomics 2020, 12, 2145-2160. [CrossRef] [PubMed] 
9. Andrejević, T.P.; Aleksic, I.; Počkaj, M.; Kljun, J.; Milivojevic, D.; Stevanović, N.L.; Nikodinovic-Runic, J.; Turel, I.; Djuran, M.I.; Glišić, B. Tailoring copper(ii) complexes with pyridine-4,5-dicarboxylate esters for anti-: Candida activity. Dalton Trans. 2021, 50, 2627-2638. [CrossRef] [PubMed]

10. Velo-Gala, I.; Barceló-Oliver, M.; Gil, D.M.; González-Pérez, J.M.; Castiñeiras, A.; Domínguez-Martín, A. Deciphering the H-Bonding Preference on Nucleoside Molecular Recognition through Model Copper(II) Compounds. Pharmaceuticals 2021, 14, 244. [CrossRef]

11. Yang, Y.; Huang, Q.; Payne, G.F.; Sun, R.; Wang, X. A highly conductive, pliable and foldable Cu/cellulose paper electrode enabled by controlled deposition of copper nanoparticles. Nanoscale 2019, 11, 725-732. [CrossRef] [PubMed]

12. Kwon, Y.T.; Kim, Y.S.; Lee, Y.; Kwon, S.; Lim, M.; Song, Y.; Choa, Y.H.; Yeo, W.H. Ultrahigh Conductivity and Superior Interfacial Adhesion of a Nanostructured, Photonic-Sintered Copper Membrane for Printed Flexible Hybrid Electronics. ACS Appl. Mater. Interfaces 2018, 10, 44071-44079. [CrossRef] [PubMed]

13. Zhang, Y.; Zhang, L.; Cui, K.; Ge, S.; Cheng, X.; Yan, M.; Yu, J.; Liu, H. Flexible electronics based on micro/nanostructured paper. Adv. Mater. 2018, 30, 1801588. [CrossRef]

14. Chan, G.H.; Zhao, J.; Hicks, E.M.; Schatz, G.C.; Van Duyne, R.P. Plasmonic properties of copper nanoparticles fabricated by nanosphere lithography. Nano Lett. 2007, 7, 1947-1952. [CrossRef]

15. Huang, C.-L.; Kumar, G.; Sharma, G.D.; Chen, F.-C. Plasmonic effects of copper nanoparticles in polymer photovoltaic devices for outdoor and indoor applications. Appl. Phys. Lett. 2020, 116, 253302. [CrossRef]

16. Gu, Z.; Shen, H.; Shang, L.; Lv, X.; Qian, L.; Zheng, G. Nanostructured Copper-Based Electrocatalysts for CO 2 Reduction. Small Methods 2018, 2, 1800121. [CrossRef]

17. Luc, W.; Fu, X.; Shi, J.; Lv, J.J.; Jouny, M.; Ko, B.H.; Xu, Y.; Tu, Q.; Hu, X.; Wu, J.; et al. Two-dimensional copper nanosheets for electrochemical reduction of carbon monoxide to acetate. Nat. Catal. 2019, 2, 423-430. [CrossRef]

18. Kuroda, K.; Keller, P.; Kawasaki, H. Mild synthesis of single-nanosized plasmonic copper nanoparticles and their catalytic reduction of methylene blue. Colloids Interface Sci. Commun. 2019, 31, 100187. [CrossRef]

19. Gao, F.; Pang, H.; Xu, S.; Lu, Q. Copper-based nanostructures: Promising antibacterial agents and photocatalysts. Chem. Commun. 2009, 3571-3573. [CrossRef] [PubMed]

20. Mahmoodi, S.; Elmi, A.; Hallaj-Nezhadi, S. Copper Nanoparticles as Antibacterial Agents. J. Mol. Pharm. Org. Process. Res. 2018, 6, 1-7. [CrossRef]

21. Jain, A.; Chi, K.M.; Kodas, T.T.; Hampden-Smith, M.J.; Farr, J.D.; Paffett, M.F. Chemical Vapor Deposition of Copper from (Hexafluoroacetylacetonato)(alkyne)-copper(I) Complexes via Disproportionation. Chem. Mater. 1991, 3, 995-997. [CrossRef]

22. Chi, Y.; Hsu, P.-F.; Liu, C.-S.; Ching, W.-L.; Chou, T.-Y.; Carty, A.J.; Peng, S.-M.; Lee, G.-H.; Chuang, S.-H. Fluorinated aminoalkoxide CuII complexes: New CVD precursors for deposition of copper metal. J. Mater. Chem. 2002, 12, 3541-3550. [CrossRef]

23. Toh, B.H.W.; McNeill, D.W.; Gamble, H.S. Investigation of copper layers deposited by CVD using Cu(I)hfac(TMVS) precursor. J. Mater. Sci. Mater. Electron. 2005, 16, 437-443. [CrossRef]

24. Córdoba, R.; Sesé, J.; De Teresa, J.M.M.; Ibarra, M.R.R.; Cordoba, R.; Sese, J. High-purity cobalt nanostructures grown by focused-electron-beam-induced deposition at low current. Microelectron. Eng. 2010, 87, 1550-1553. [CrossRef]

25. Córdoba, R.; Sharma, N.; Kölling, S.; Koenraad, P.M.; Koopmans, B. High-purity 3D nano-objects grown by focused-electron-beam induced deposition. Nanotechnology 2016, 27, 355301. [CrossRef] [PubMed]

26. Shawrav, M.M.; Taus, P.; Wanzenboeck, H.D.; Schinnerl, M.; Stöger-Pollach, M.; Schwarz, S.; Steiger-Thirsfeld, A.; Bertagnolli, E. Highly conductive and pure gold nanostructures grown by electron beam induced deposition. Sci. Rep. 2016, 6, 34003. [CrossRef]

27. Kodas, T.T.; Hampden-Smith, M.J. The Chemistry of Metal CVD; Wiley-VCH: Weinheim, Germany, 1994.

28. Huth, M.; Porrati, F.; Schwalb, C.; Winhold, M.; Sachser, R.; Dukic, M.; Adams, J.; Fantner, G. Focused electron beam induced deposition: A perspective. Beilstein J. Nanotechnol. 2012, 3, 597-619. [CrossRef] [PubMed]

29. Utke, I.; Hoffmann, P.; Melngailis, J. Gas-assisted focused electron beam and ion beam processing and fabrication. J. Vac. Sci. Technol. B 2008, 26, 1197-1276. [CrossRef]

30. Luisier, A.; Utke, I.; Bret, T.; Cicoira, F.; Hauert, R.; Rhee, S.-W.; Doppelt, P.; Hoffmann, P. Comparative Study of Cu Precursors for 3D Focused Electron Beam Induced Deposition. J. Electrochem. Soc. 2004, 151, C535-C537. [CrossRef]

31. Utke, I.; Luisier, A.; Hoffmann, P.; Laub, D.; Buffat, P.A. Focused-electron-beam-induced deposition of freestanding threedimensional nanostructures of pure coalesced copper crystals. Appl. Phys. Lett. 2002, 81, 3245-3247. [CrossRef]

32. Haverkamp, C.; Sarau, G.; Polyakov, M.N.; Utke, I.; dos Santos, M.V.P.; Christiansen, S.; Höflich, K. A novel copper precursor for electron beam induced deposition. Beilstein J. Nanotechnol. 2018, 9, 1220-1227. [CrossRef]

33. Berger, L.; Jurczyk, J.; Madajska, K.; Edwards, T.E.J.; Szymańska, I.; Hoffmann, P.; Utke, I. High-Purity Copper Structures from a Perfluorinated Copper Carboxylate Using Focused Electron Beam Induced Deposition and Post-Purification. ACS Appl. Electron. Mater. 2020, 2, 1989-1996. [CrossRef]

34. Reilly, W.L.; Brown, H.C. Reactions of Perfluoronitriles. I. Synthesis of Derivatives of Perfluoroamidines, N-Substituted Perfluoroamidines and Perfluorothioamides. J. Am. Chem. Soc. 1956, 78, 6032-6034. [CrossRef]

35. Hagen, D.J.; Pemble, M.E.; Karppinen, M. Atomic layer deposition of metals: Precursors and film growth. Appl. Phys. Rev. 2019, 6, 041309. [CrossRef]

36. Krisyuk, V.V.; Aloui, L.; Prud’homme, N.; Sarapata, B.; Senocq, F.; Samélor, D.; Vahlas, C. CVD of pure copper films from a novel amidinate precursor. ECS Trans. 2009, 25, 581-586. [CrossRef] 
37. Krisyuk, V.; Aloui, L.; Prud'homme, N.; Sysoev, S.; Senocq, F.; Samélor, D.; Vahlas, C. CVD of pure copper films from amidinate precursor. Electrochem. Solid State Lett. 2011, 14, D26-D29. [CrossRef]

38. Chua, D.; Kim, S.B.; Li, K.; Gordon, R. Low temperature chemical vapor deposition of cuprous oxide thin films using a copper(i) amidinate precursor. ACS Appl. Energy Mater. 2019, 2, 7750-7756. [CrossRef]

39. Li, Z.; Barry, S.T.; Gordon, R.G. Synthesis and characterization of copper(I) amidinates as precursors for atomic layer deposition (ALD) of copper metal. Inorg. Chem. 2005, 44, 1728-1735. [CrossRef] [PubMed]

40. Mishra, S.; Daniele, S. Metal-Organic Derivatives with Fluorinated Ligands as Precursors for Inorganic Nanomaterials. Chem. Rev. 2015, 115, 8379-8448. [CrossRef]

41. Szymańska, I.B. Gaseous phase studies of new copper(II) carboxylate complexes with tert-butylamine as potential precursors for chemical vapor deposition (CVD). Polyhedron 2013, 50, 200-207. [CrossRef]

42. Piszczek, P.; Szymańska, I.B.; Talik, E.; Heimann, J. Deposition of thin copper layers using copper(II) carboxylate complexes with tert-butylamine as new CVD precursors. Chem. Vap. Depos. 2013, 19, 251-259. [CrossRef]

43. Brown, D.J.; Chisholm, M.H.; Gallucci, J.C. Amidinate-carboxylate complexes of dimolybdenum and ditungsten: M2(O2CR) 2((NiPr)2CR')2. Preparations, molecular and electronic structures and reactions. J. Chem. Soc. Dalton Trans. 2008, 1615-1624. [CrossRef] [PubMed]

44. Mendoza, I.; Curado, N.; Carrasco, M.; Álvarez, E.; Peloso, R.; Rodríguez, A.; Carmona, E. Synthesis and structure of mixed carboxylate-aminopyridinate and -amidinate complexes of dimolybdenum and ditungsten. Inorganica Chim. Acta 2015, 424, 120-128. [CrossRef]

45. Munzeiwa, W.A.; Nyamori, V.O.; Omondi, B. $\mathrm{Zn}(\mathrm{II})$ and $\mathrm{Cu}(\mathrm{II})$ unsymmetrical formamidine complexes as effective initiators for ring-opening polymerization of cyclic esters. Appl. Organomet. Chem. 2018, 32, e4247. [CrossRef]

46. Szłyk, E.; Szymańska, I. Studies of new volatile copper(I) complexes with triphenylphosphite and perfluorinated carboxylates. Polyhedron 1999, 18, 2941-2948. [CrossRef]

47. Frisch, M.J.; Trucks, G.W.; Schlegel, H.B.; Scuseria, G.E.; Robb, M.A.; Cheeseman, J.R.; Scalmani, G.; Barone, V.; Petersson, G.A.; Nakatsuji, H.; et al. G16_C01; Gaussian, Inc.: Wallingford, CT, USA, 2016.

48. Zhao, Y.; Truhlar, D.G. The M06 suite of density functionals for main group thermochemistry, thermochemical kinetics, noncovalent interactions, excited states, and transition elements: Two new functionals and systematic testing of four M06-class functionals and 12 other function. Theor. Chem. Acc. 2008, 120, 215-241. [CrossRef]

49. John Wiley \& Sons. SpectraBase. Available online: https:/ / spectrabase.com/ (accessed on 29 May 2021).

50. Barry, S.T. Amidinates, guanidinates and iminopyrrolidinates: Understanding precursor thermolysis to design a better ligand. Coord. Chem. Rev. 2013, 257, 3192-3201. [CrossRef]

51. John Wiley \& Sons. SpectraBase Compound ID=JSNx6EfxlY2 SpectraBase Spectrum ID=3ZkQWtxcvyC. Available online: https:/ / spectrabase.com/spectrum/3ZkQWtxcvyC (accessed on 29 May 2021).

52. Majima, T.; Sugita, K.; Nakao, A.; Matsunuma, S.; Abe, K. Synthesis of thin layer of fluorinated polymer by laser CVD—direct synthesis of perfluoropolyether thin film on surface by oxidative polymerization of a perfluoropropene-oxygen mixture using an ArF excimer laser. J. Photopolym. Sci. Technol. 1993, 6, 421-428. [CrossRef]

53. John Wiley \& Sons. SpectraBase Compound ID=8A1dEqurmmH SpectraBase Spectrum ID=G4CBuKNSKtQ. Available online: https:/ / spectrabase.com/spectrum/G4CBuKNSKtQ (accessed on 29 May 2021).

54. John Wiley \& Sons. SpectraBase Compound ID=n8DC1v4dvL SpectraBase Spectrum ID=Big2BLmUPf2. Available online: https: / / spectrabase.com/spectrum/Big2BLmUPf2 (accessed on 29 May 2021).

55. John Wiley \& Sons. SpectraBase Compound ID=4G3cv2HmDfG SpectraBase Spectrum ID=89U74D3zedG. Available online: https:/ / spectrabase.com/spectrum/89U74D3zedG (accessed on 29 May 2021).

56. Shurvell, H.F.; Bulmer, J.T. The infrared and Raman spectra of pentafluoropropionitrile. J. Fluor. Chem. 1972, 1, 391-406. [CrossRef]

57. John Wiley \& Sons. SpectraBase Compound ID=COBj6FpC1Cb SpectraBase Spectrum ID=4dr5ESO3mVP. Available online: https:/ / spectrabase.com/spectrum/4dr5ESO3mVP (accessed on 29 May 2021).

58. Run Nielsen, J.; Claassen, H.H.; Smith, D.C. Infrared and Raman Spectra of Fluorinated Ethylenes. V. Hexafluoropropene. J. Chem. Phys. 1952, 20, 1916-1919. [CrossRef]

59. U.S. Secretary of Commerce on Behalf of the United States of America. Perfluoro-n-Pentanoic Acid.. Available online: https: / / webbook.nist.gov / cgi/cbook.cgi?ID=C2706903\&Mask=80 (accessed on 29 May 2021).

60. Yuan, Q.; Zhou, T.; Li, L.; Zhang, J.; Liu, X.; Ke, X.; Zhang, A. Hydrogen bond breaking of TPU upon heating: Understanding from the viewpoints of molecular movements and enthalpy. RSC Adv. 2015, 5, 31153-31165. [CrossRef]

61. John Wiley \& Sons. SpectraBase Compound ID=JSNx6EfxlY2 SpectraBase Spectrum ID=C0XmNpe0v68. Available online: https:/ / spectrabase.com/spectrum/C0XmNpe0v68 (accessed on 29 May 2021).

62. Stoffels, W.W.; Stoffels, E.; Tachibana, K. Polymerization of fluorocarbons in reactive ion etching plasmas. J. Vac. Sci. Technol. A Vac. Surf. Films 1998, 16, 87-95. [CrossRef]

63. Rijs, N.J.; O'Hair, R.A.J.J. Forming trifluoromethylmetallates: Competition between decarboxylation and C-F bond activation of group 11 trifluoroacetate complexes, [CF 3CO 2ML]. Dalton Trans. 2012, 41, 3395-3406. [CrossRef] [PubMed]

64. Lacko, M.; Papp, P.; Szymańska, I.B.; Szłyk, E.; Matejčík, Š. Electron interaction with copper(II) carboxylate compounds. Beilstein J. Nanotechnol. 2018, 9, 384-398. [CrossRef] 